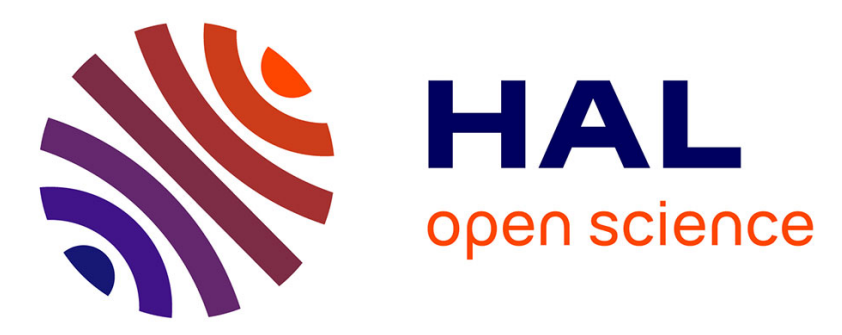

\title{
Optimal labor market policy with search frictions and risk-averse workers
}

\author{
Jean-Baptiste Michau
}

\section{To cite this version:}

Jean-Baptiste Michau. Optimal labor market policy with search frictions and risk-averse workers. 2012. hal-00757173

\section{HAL Id: hal-00757173 \\ https://hal.science/hal-00757173}

Preprint submitted on 26 Nov 2012

HAL is a multi-disciplinary open access archive for the deposit and dissemination of scientific research documents, whether they are published or not. The documents may come from teaching and research institutions in France or abroad, or from public or private research centers.
L'archive ouverte pluridisciplinaire HAL, est destinée au dépôt et à la diffusion de documents scientifiques de niveau recherche, publiés ou non, émanant des établissements d'enseignement et de recherche français ou étrangers, des laboratoires publics ou privés. 


\title{
ECOLE POLYTECHNIQUE
}

\section{OPTIMAL LABOR MARKET POLICY WITH SEARCH} FRICTIONS AND RISK-AVERSE WORKERS

\author{
Jean-Baptiste MICHAU
}

Cahier $n^{\circ}$ 2012-34

\section{DEPARTEMENT D'ECONOMIE}

Route de Saclay

91128 PALAISEAU CEDEX

(33) 169333033

http://www.economie.polytechnique.edu/ mailto:chantal.poujouly@polytechnique.edu 


\title{
Optimal Labor Market Policy with Search Frictions and Risk-Averse Workers
}

\author{
Jean-Baptiste Michau* \\ Ecole Polytechnique
}

November 2012

\begin{abstract}
This paper characterizes the optimal policy within a dynamic search model of the labor market with risk-averse workers. In a first-best allocation of resources, unemployment benefits should provide perfect insurance against the unemployment risk, layoff taxes are necessary to induce employers to internalize the cost of dismissing an employee but should not be too high in order to allow a desirable reallocation of workers from low to high productivity jobs, hiring subsidies are needed to partially offset the adverse impact of layoff taxes on job creation and payroll taxes should be approximately equal to zero. I obtain an optimal rate of unemployment which is, in general, different from the output maximizing rate of unemployment. When workers have some bargaining power, which prevents the provision of full insurance, it is optimal to reduce the rate of job creation below the output maximizing level in order to lower wages and increase the level of unemployment benefits. Thus, layoff taxes should typically exceed hiring subsidies which generates enough surplus to finance at least some of the unemployment benefits. The inclusion of moral hazard does not change this conclusion, unless workers have low bargaining power.
\end{abstract}

Keywords: Employment protection, Hiring subsidies, Optimal rate of unemployment, Unemployment insurance

JEL Classification: D60, E62, H21, J38, J65

*I am grateful to Pierre Cahuc, Pierre Chaigneau, Pieter Gautier, Philipp Kircher, Etienne Lehmann, Alan Manning, Barbara Petrongolo, Steve Pischke, Christopher Pissarides, Fabien Postel-Vinay, Johannes Spinnewijn, Jean Tirole and to seminar participants at the LSE, EEA-ESEM 2009 (Barcelona, Spain) and the Centre for Structural Econometrics of the University of Bristol (UK) for useful comments and suggestions. Contact: Jean-Baptiste.Michau@polytechnique.edu 


\section{Introduction}

The design of labor market institutions is among the key determinants of the economic success or failure of a nation. There is nevertheless no consensus among economists about the optimal design of such institutions and, in many industrialized countries, the subject remains at the center of considerable controversies among policy makers. In particular, there appears to be a fundamental trade-off between the demand for insurance of riskaverse workers and the macroeconomic efficiency of the labor market which should allocate workers to the jobs where they are going to be most productive. Hence, a typical concern is that government interventions aimed at improving insurance, such as the provision of unemployment benefits or employment protection, might have adverse consequences for aggregate production.

Search frictions are a major source of the trade-off between insurance and production since they generate some unemployment and they prevent an immediate reallocation of workers from low to high productivity jobs. ${ }^{1}$ A macroeconomic framework is required to analyze this trade-off since search frictions induce non-trivial general equilibrium effects on job creation and job destruction which are key to the reallocation process of workers. Furthermore, wages could be affected by macroeconomic variables such as the expected length of an unemployment spell. These general equilibrium effects imply that different labor market policy instruments do interact among each other. Hence, these instruments jointly influence the provision of insurance and the efficiency of production. They therefore need to be analyzed jointly.

A search model à la Mortensen-Pissarides (1994) with risk-averse workers captures the trade-off between insurance and production as well as the aforementioned general equilibrium effects and allows for a joint analysis of the different policy instruments. In this paper, I therefore rely on such a framework to determine the main characteristics of an optimal labor market policy. Employment protection takes the form of layoff taxes. The government can also provide hiring subsidies in order to encourage job creation. The generosity of unemployment insurance is determined by the level of unemployment benefits. Payroll taxes could be used to raise revenue. If they happen to take negative values, payroll taxes could also be seen as employment subsidies. Importantly, it is assumed throughout, as in most of the literature on the topic, that the government is the sole provider of unemployment insurance. ${ }^{2}$

\footnotetext{
${ }^{1}$ The other major source of the trade-off is moral hazard which will be allowed for in the last section of this paper.

${ }^{2}$ The implicit contract literature has argued that risk-neutral firms should be expected to provide unemployment benefits to risk-averse workers; see, for instance, Baily (1974a) or Azariadis (1975). However, in reality, such contracts remain the exception rather than the rule. Thus, although somewhat $a d-h o c$, the assumption that the private market does not provide insurance seems reasonable and has the merit of making the analysis transparent. This assumption has nevertheless been relaxed in the optimal
} 
I begin by deriving the optimal allocation of resources chosen by a planner who wants to maximize the welfare of workers subject to matching frictions and to a resource constraint. In this ideal setup, full insurance is provided and aggregate output, net of recruitment costs, is maximized. It turns out that this first-best allocation can be implemented in a decentralized economy when workers are wage takers. To obtain an efficient rate of job destruction, layoff taxes should induce firms to internalize the social costs and benefits of dismissing a worker. The costs consist of the unemployment benefits that will need to be paid and of the forgone payroll taxes; while the benefits correspond to the value of a desirable reallocation of the worker from a low to a high productivity job. Hiring subsidies are needed to partially offset the negative impact of layoff taxes on job creation. Finally, and perhaps surprisingly, payroll taxes should optimally be approximately set equal to zero. Thus, both unemployment benefits and hiring subsidies are almost entirely financed from layoff taxes.

Importantly, my analysis naturally defines a welfare maximizing optimal rate of unemployment. If full insurance cannot be provided, then this optimal rate of unemployment is generically different from the output maximizing rate of unemployment commonly emphasized in the search and matching literature.

I then turn to the characterization of the optimal policy when workers have some bargaining power, which prevents the provision of full insurance. Relying on numerical simulations, I show that the planner typically chooses to set layoff taxes higher than hiring subsidies such as to discourage the entry of firms with a vacant position. This reduces market tightness and, hence, wages which, by relaxing the resource constraint, makes it possible to increase the level of unemployment benefits.

I then allow for moral hazard. This generates the opposite possibility that insurance may be too high, in which case the planner wants to increase market tightness. However, the simulations reveal that an insufficient provision of insurance remains the main concern whenever workers have substantial bargaining power. Thus, moral hazard does not seem to be the most important feature of the fundamental trade-off between the provision of insurance and the level of aggregate production. General equilibrium effects on wages and on job creation and job destruction seem to be at least as important.

\subsection{Related Literature}

This paper is related to the extensive economic literature on the optimal design of labor market institutions. The main strand of this literature focuses on the provision of unemployment insurance. In their seminal work, Shavell and Weiss (1979) and Hopenhayn and Nicolini (1997) focused on a single unemployment spell and derived the optimal

policy analyses of Chetty Saez (2010) and Fella Tyson (2011). 
time profile of unemployment benefits when moral hazard introduces a trade-off between the provision of insurance and the provision of incentives to search. By contrast, Baily (1974b) and Chetty (2006) focused on the level of benefits, rather than their time profile, in a framework which allows for multiple spells. Importantly, these contributions assume that unemployment benefits are exclusively financed from payroll taxes and abstract from general equilibrium effects.

The literature on employment protection is mostly positive, rather than normative. The crux of the academic debate is about the impact of layoff taxes on the level of employment; with the underlying presumption that layoff taxes are desirable if they decrease the number of jobless workers. Bentolila and Bertola (1990) showed, in a partial equilibrium context, that firing costs have a larger impact on job destruction than on job creation and should therefore be beneficial for employment. This conclusion was challenged by the general equilibrium analysis with employment lotteries of Hopenhayn and Rogerson (1993). Ljungqvist (2002) showed that, in search models à la Mortensen-Pissarides, layoff costs increase employment if initial wages are negotiated before a match is formed, while the opposite is true if bargaining only occurs after the match is formed. Importantly, these contributions either assume that workers are risk-neutral or that financial markets are complete. Hence, they do not generate any trade-off between insurance and production efficiency and cannot give sensible measures of the welfare implications of layoff taxes. These analyses are therefore hardly informative about the optimal level of employment protection.

While most papers ignore the interaction between different policy instruments, there are two important exceptions which are closely related to this work. First, Mortensen and Pissarides $(2003)^{3}$ analyze labor market policies in a dynamic search model with risk-neutral workers. Since there is no need for insurance, the best that the government can do is to maximize output net of recruitment costs. If the Hosios (1990) condition holds, i.e. the bargaining power of workers is equal to the elasticity of the matching function, then it is optimal for the government not to intervene; while, if it does not hold, policy parameters should only be used to correct for the resulting search externalities. An important insight is that the introduction of unemployment benefits has a positive impact on wages and, therefore, increases job destruction. This should be offset by higher layoff taxes. Hiring subsidies should also be increased such as to leave the rate of job creation unchanged. ${ }^{4}$ However, with risk-neutral workers, there is no trade-off between insurance and production. ${ }^{5}$

\footnotetext{
${ }^{3}$ See also Mortensen Pissarides (1999) and Pissarides (2000, chapter 9).

${ }^{4}$ Importantly, Mortensen and Pissarides (2003) do not impose an aggregate resource constraint. When such a constraint is imposed, the level of unemployment benefits can no longer be set as a free parameter. This explains why the resource constraint plays a key role in my characterization of the optimal policy when workers have some bargaining power.

${ }^{5}$ Interestingly, Schuster (2010) extends the Mortensen Pissarides (2003) framework by adding a job
} 
The second closely related paper is Blanchard Tirole (2008) which proposes a joint derivation of optimal unemployment insurance and employment protection in a static context with risk-averse workers. In their benchmark model, they show that unemployment benefits should be entirely financed from layoff taxes, rather than payroll taxes, in order to induce firms to internalize the social cost of unemployment. ${ }^{6}$ However, their static framework does not have a job creation margin and therefore ignores the adverse effect of layoff taxes on job creation. In fact, as we shall see, in a dynamic context the share of unemployment benefits financed from payroll taxes is determined by the job creation side of the economy. Also, and more fundamentally, a static approach entails an entirely negative view of unemployment; whereas in a dynamic setting an unemployed worker is a useful input in the matching process. In fact, a well-known result from the search and matching literature is that, to maximize output in an economy without governmental intervention, the bargaining power of workers that satisfies the Hosios condition actually maximizes the rate of job destruction!

Finally, this paper is also related to a small literature on policy analyses within dynamic search models of the labor market with risk-averse workers. Cahuc Lehmann (2000), Fredriksson Holmlund (2001) and Lehmann van der Linden (2007) focus on the optimal provision of unemployment insurance under moral hazard. All three contributions pay particular attention to the general equilibrium effects of unemployment insurance. More specifically, they emphasize that an increase in benefits leads to an increase in wages which reduces the rate of job creation. Along similar lines, Krusell Mukoyama Sahin (2010) investigate the optimal provision of unemployment insurance in a search model where the accumulation of risk-free savings is the only source of private insurance available to risk-averse workers. They show that, even in the absence of moral hazard, the adverse impact of unemployment insurance on job creation is so large that the optimal replacement ratio is close to zero. It should be mentioned that none of these papers allow for the possibility of using hiring subsidies and firing taxes to control the rates of job creation and job destruction.

Acemoglu Shimer $(1999,2000)$ showed, in the context of directed search with riskaverse workers, that higher unemployment benefits could improve the quality, and productivity, of job-worker matches. By contrast, in this paper, match quality is unrelated to the length of unemployment. Alavarez Veracierto (2000, 2001) rely on calibrated search models with risk-averse workers to investigate the effects of different labor market poli-

acceptance margin. He shows that the implementation of the optimal policy requires additional policy instruments.

${ }^{6}$ This policy, often referred to as "experience rating", was originally proposed by Feldstein (1976). Other related contributions on the topic, and mostly in favor of such policy, include Topel Welch (1980), Topel (1983), Wang Williamson (2002), Cahuc Malherbet (2004), Mongrain Roberts (2005), Cahuc Zylberberg (2008) and L'Haridon Malherbet (2009). 
cies. However, their approach is entirely positive and does not attempt to characterize optimal policies. ${ }^{7}$

In a closely related paper, Coles and Masters (2006) show that there is some complementarity between the provision of unemployment insurance and that of hiring subsidies. The idea is that, by boosting the job creation rate, subsidies exert a downward pressure on unemployment and, hence, on the cost of providing unemployment insurance. However, their model does not have an endogenous job destruction margin and, therefore, cannot be used to determine the optimal level of employment protection.

This paper begins, in section two, with a brief reminder of some of the key features of the Mortensen-Pissarides (1994) framework. In the following section, I derive the first-best policy, which then serves as a benchmark. Section four relies on numerical simulations to investigate optimal policies when workers have some bargaining power. Finally, the last section deals with the consequences of moral hazard. This paper ends with a conclusion.

\section{Search Model}

Before characterizing the optimal labor market policies, it is necessary to describe the main features of the dynamic search model on which I rely throughout this paper. The structure of the economy corresponds to the standard Mortensen-Pissarides (1994) framework. Time is continuous. Production requires that vacant jobs and unemployed workers get matched, which occurs at rate:

$$
m=m(u, v)
$$

where $u$ stands for the number of unemployed and $v$ for that of vacancies. For simplicity, the mass of workers is normalized to one, so that $u$ also stands for the rate of unemployment. The matching function $m$ is increasing in both arguments, exhibits decreasing marginal product to each input and satisfies constant returns to scale.

Let $\theta$ denote market tightness which is defined as the ratio of vacancies to unemployment, i.e. $\theta=v / u$. The rate at which vacant jobs meet unemployed workers is given by:

$$
\frac{m(u, v)}{v}=m\left(\frac{u}{v}, 1\right)=m\left(\frac{1}{\theta}, 1\right)=q(\theta)
$$

where $q(\theta)$ is a decreasing function of $\theta$. Similarly the rate at which unemployed workers

\footnotetext{
${ }^{7}$ Ljungqvist Sargent (2008) also investigate the interactions between unemployment insurance and employment protection in a positive analysis of the labor market, but with risk-neutral workers.
} 
find jobs is:

$$
\frac{m(u, v)}{u}=m(1, \theta)=\theta q(\theta) .
$$

Clearly, the constant returns to scale assumption implies that market tightness is the key parameter which summarizes labor market conditions for both unemployed workers and recruiting firms. The elasticity of the matching function is defined as: ${ }^{8}$

$$
\eta(\theta)=-\frac{\theta}{q(\theta)} \frac{d q(\theta)}{d \theta}
$$

The other main feature of the Mortensen-Pissarides model is that the productivity of a match is subject to idiosyncratic shocks. Production starts at maximal productivity, normalized to 1 . The idea is that recruiting firms are prosperous and will make a very efficient use of their additional worker. At Poisson rate $\lambda$, the match is hit by a productivity shock and a new productivity $x \in[\psi, 1]$ is randomly drawn from the c.d.f. $G(x)$. The match dissolves if the new productivity is below a threshold $R$, to be determined.

Note that assuming an initial match productivity equal to 1 ensures that the productivity of recruiting firms is always well above the job destruction threshold $R$ (which is a natural assumption to make as, otherwise, these firms would not be posting a vacancy in the first place). ${ }^{9}$ Moreover, the importance of this assumption, which is standard in the search and matching literature, should not be overstated. Indeed, firms base their recruiting decisions on the expected net present value of a new match rather than on its initial productivity.

The remaining features of the model will be given in the following section as the optimal policy is being derived.

\section{$3 \quad$ First-Best Policy}

The optimal policy is derived in two steps. First, I characterize the optimal allocation of resources chosen by a benevolent social planner. Then, I turn to its implementation in a decentralized economy with free entry of risk-neutral firms.

\footnotetext{
${ }^{8}$ Note that $\eta$ is the elasticity of the matching function with respect to the number of unemployed, i.e. $\eta=\frac{u}{m} \frac{\partial m}{\partial u}$, and $1-\eta$ the elasticity with respect to the number of vacancies, i.e. $1-\eta=\frac{v}{m} \frac{\partial m}{\partial v}$.

${ }^{9}$ This justification implicitly considers that, once the firm has spent the necessary amount of time to recruit a worker, the productivity of that worker will be primarily determined by the productivity of the firm. Relaxing this assumption and allowing for stochastic job matching is beyond the scope of this paper. See Schuster (2010) for a related analysis which does allow for a job acceptance margin resulting from stochastic match productivity at recruitment.
} 


\subsection{Optimal Allocation}

The optimal allocation maximizes a utilitarian social welfare function subject to a resource constraint and to the search frictions that characterize the labor market. It is therefore the solution to the following problem:

$$
\begin{aligned}
& \qquad \begin{array}{c}
\max _{\{\theta, R, b, w\}} \int_{0}^{\infty} e^{-r t}[(1-u) v(w)+u v(z+b)] d t \\
\text { subject to } \quad \dot{u}=\lambda G(R)(1-u)-\theta q(\theta) u \\
\dot{y}=\theta q(\theta) u+\lambda(1-u) \int_{R}^{1} s d G(s)-\lambda y \\
(1-u) w+u b=y-c \theta u
\end{array}
\end{aligned}
$$

where $r$ stands for the planner's (or workers') discount rate, $w$ for the net wage that an employee receives, $z$ for the value of leisure, $b$ for unemployment benefits, $y$ for the aggregate output of the economy and $c$ for the flow cost of posting a vacancy. The instantaneous utility function of risk-averse workers is denoted by ${ }^{10} v($.$) , which is increasing$ and concave.

The planner's objective is to maximize intertemporal social welfare, which, according to a utilitarian criterion, is composed at each instant of the instantaneous utility of $u$ unemployed and $1-u$ employed workers. ${ }^{11}$ The first constraint depicts the dynamics of unemployment, driven by the difference between the job destruction flow and the job creation flow. A match dissolves when it is hit by an idiosyncratic shock that generates a new productivity below the threshold $R$, which occurs at rate $\lambda G(R)$. This rate of job destruction applies to the mass $1-u$ of existing matches. Job creation is simply equal to the rate at which unemployed workers find jobs, $\theta q(\theta)$, multiplied by the mass $u$ of job seekers. It should be emphasized that this first constraint captures the fact that even the social planner is subject to matching frictions. The second constraint gives the dynamics of aggregate output, $y$. At each instant, $\theta q(\theta) u$ new matches are formed and each of these has a productivity of 1 . The $1-u$ existing jobs are hit at rate $\lambda$ by idiosyncratic shocks which destroy their current productivity and replaces it, in case of survival, by a randomly drawn number greater or equal to the threshold $R$. Finally, any feasible allocation must

\footnotetext{
${ }^{10}$ In the previous section $v$ denoted the number of vacancies. However, this variable will not appear in the rest of the text (except when I define the matching function under moral hazard in the last section of the paper). I focus instead on $\theta$ and $u$ and, where needed, $v$ is just replaced by $\theta u$.

${ }^{11}$ An alternative would be to maximize the weighted average between the expected utility of an employed and of an unemployed worker. Such objective function would be more appropriate in a political economy context focusing on the conflict between insiders and outsiders. However, without time discounting, this would be identical to the planner's objective of this paper.
} 
satisfy the economy's aggregate resource constraint. ${ }^{12}$ The expenses, composed of the wages paid to the employed and the benefits paid to the unemployed, cannot exceed total output net of the resources allocated to recruitment, which amount to a flow cost $c$ paid for each of the $\theta u$ vacancies. The planner's control variables are market tightness $\theta$, the threshold productivity $R$, the net wage $w$ and the level of unemployment benefits $b$. The state variables are unemployment $u$ and aggregate output $y$.

The planner's problem is straightforward to solve using standard optimal control techniques. The first characteristic of the optimal allocation is that workers are offered perfect insurance against the unemployment risk:

$$
w=z+b,
$$

which is a direct consequence of workers' risk aversion, i.e. of the concavity of $v($.$) . This$ can be combined with the resource constraint, $(6 \mathrm{c})$, to give the optimal value of $w$ and $b$ :

$$
\begin{aligned}
w & =y-c \theta u+z u, \\
b & =y-c \theta u-z(1-u) .
\end{aligned}
$$

Note that perfect insurance necessitates a replacement ratio smaller than one whenever the value $z$ of leisure is strictly positive.

The optimal values of $\theta$ and $R$ are implicitly determined by the following two firstorder conditions:

$$
\begin{gathered}
{[1-\eta(\theta)] \frac{1-R}{r+\lambda}=\frac{c}{q(\theta)},} \\
R=z+\frac{\eta(\theta)}{1-\eta(\theta)} c \theta-\frac{\lambda}{r+\lambda} \int_{R}^{1}(s-R) d G(s),
\end{gathered}
$$

where $\eta(\theta)$ denotes the elasticity of the matching function, cf. equation (4). These two optimality conditions are exactly identical to the ones derived in Pissarides (2000, chapter 8 ) for net output maximization. ${ }^{13}$ This is not surprising as, when nothing prevents the provision of full insurance, the best that the planner can do is to maximize output. The first equation, (10), guarantees an optimal rate of job creation. The cost of job creation consists of the flow cost of having a vacancy, $c$, multiplied by the expected time that has to be spent before a worker could be found, $1 / q(\theta)$. The value of a newly created match is equal to $(1-R) /(r+\lambda)$. However, optimally, recruitment costs should only

\footnotetext{
${ }^{12}$ Replacing the resource constraint $(6 \mathrm{c})$ by an intertemporal resource constraint would not change any of the results provided that the interest rate at which the planner can transfer resources across time is equal to the planner's discount rate.

${ }^{13}$ Under risk neutrality, the objective of the planner is to maximize the net present value of the flow of net output, where this flow is given by $y-c \theta u+u z$.
} 
absorb a fraction $1-\eta(\theta)$ of this value as, otherwise, there is too much job creation and an excessive amount of resources is allocated to recruitment. Equation (11) ensures an optimal rate of job destruction. In the static context of Blanchard Tirole (2008), the optimal threshold is just equal to the value of leisure, i.e. $R=z$. Making the model dynamic yields two extra terms. First, when a low productivity job is destroyed, the corresponding worker returns to unemployment with the hope of finding a new job with productivity 1 . To make this explicit, the corresponding term of equation (11) can be rewritten, using (10), as:

$$
\begin{aligned}
\frac{\eta(\theta)}{1-\eta(\theta)} c \theta & =\theta q(\theta) \eta(\theta) \frac{1-R}{r+\lambda} \\
& =\theta q(\theta)\left[\frac{1-R}{r+\lambda}-\frac{c}{q(\theta)}\right] .
\end{aligned}
$$

This says that, once a job is destroyed, an unemployed worker gets matched at rate $\theta q(\theta)$ which generates a social value of $(1-R) /(r+\lambda)$ net of the expected recruitment cost $c / q(\theta)$. In other words, the threshold $R$ has to be sufficiently high to induce an efficient reallocation of workers from low to high productivity jobs. The second additional term to the expression for the optimal threshold $R$ corresponds to the option value of a match. Even if current productivity is very low, keeping the match alive preserves the option of being hit by an idiosyncratic shock that restores a profitable level of productivity. The option value decreases the optimal threshold $R$.

In steady state, the optimal allocation of resources chosen by a benevolent social planner is fully characterized by the first-order conditions (7), (10) and (11) together with the constraints (6a), (6b) and (6c) with $\dot{u}=\dot{y}=0$.

\subsection{Implementation}

Having characterized the optimal allocation, I now turn to its implementation in a decentralized economy. Throughout the paper, I restrict the government to rely exclusively on the following four policy instruments: unemployment benefits $b$, payroll taxes $\tau$, layoff taxes $F$ and hiring subsidies $H$. I choose to focus on these four as they are the most natural instruments through which the government can in practice affect the labor market. ${ }^{14}$ Moreover, as we shall see in this section, they are sufficient to implement the first-best allocation of resources in a benchmark case.

In the decentralized economy, four stages of interest can be distinguished.

- Stage 1: The government chooses the level of unemployment benefits $b$, payroll

\footnotetext{
${ }^{14}$ In practice, the minimum wage also is a very important labor market policy instrument. However, any meaningful analysis of the minimum wage must allow for heterogeneity among workers, which is beyond the scope of this paper.
} 
taxes $\tau$, layoff taxes $F$ and hiring subsidies $H$.

- Stage 2: Entrepreneurs decide whether or not to create a firm with a vacant position.

- Stage 3: Once a match occurs, the employer and employee agree on a wage rate.

- Stage 4: Each firm chooses a threshold productivity $R$ below which the match dissolves.

I now proceed backward and start by determining the threshold $R$ chosen at Stage 4 by a risk-neutral employer. The asset value of a producing firm with productivity $x$, $J(x)$, solves the following Bellman equation:

$$
r J(x)=x-(w+\tau)+\lambda \int_{R}^{1} J(s) d G(s)-\lambda G(R) F-\lambda J(x),
$$

where $r$ denotes the risk-free interest rate, which is taken to be identical to the planner's discount rate, $w$ the net wage that the worker receives and $w+\tau$ the gross wage paid by the employer. This Bellman equation states that, for a firm, the flow return from having a filled job with productivity $x$ is equal to the instantaneous surplus it generates to which the possibility of a change in productivity should be added. An idiosyncratic shock destroys the value of the firm at the current productivity and replaces it by either a corresponding expression, if the new productivity is above the threshold, or by the cost of layoff ${ }^{15}$, if the match is to be destroyed. As $J(x)$ is strictly increasing in $x$, the employer chooses a job destruction threshold $R$ which is determined by:

$$
J(R)=-F
$$

This says that, at the threshold, the employer is indifferent between closing down and continuing the relationship. Simple algebra ${ }^{16}$ on (13) and (14) gives the expression for the value of $R$ chosen by firms:

$$
R=w+\tau-r F-\frac{\lambda}{r+\lambda} \int_{R}^{1}(s-R) d G(s)
$$

The threshold productivity is smaller than the cost of labor because of the firing tax and of the option value of continuing the match. Note that, for this to be possible, firms

\footnotetext{
${ }^{15}$ Throughout this paper, it is assumed that firms are able to pay the layoff tax. Blanchard and Tirole (2008) investigate the consequences of having employers constrained by shallow pockets. See also Tirole (2010) for a deeper analysis on the topic which allows for extended liability to third parties in the context of employment protection.

${ }^{16} \mathrm{An}$ analytic expression for the function $J($.$) can be obtained by taking the difference between equation$ (13) evaluated at $x$ and the same equation evaluated at $R$. This expression for $J($.$) can then be substituted$ into (13) evaluated at $R$. Finally, using the value of $J(R)$ given by (14) yields (15).
} 
must be able to borrow and lend from perfect financial markets, an assumption that is maintained throughout this paper. Equation (15) is our first implementability constraint: the decentralized job destruction condition.

Let us now turn to the determination of the wage rate that occurs at Stage 3. The formation of a match generates a surplus that needs to be shared between the two parties. But, from equation (7), at the optimum the net wage $w$ paid to a worker must be equal to the wage equivalent of being unemployed $z+b$. This immediately leads to the following lemma:

Lemma 1 A necessary condition to implement the first-best allocation is that workers are wage takers and that all the match surplus is captured by the firm. This guarantees that, as desired:

$$
w=z+b .
$$

The intuition for this result is straightforward. If workers have some bargaining power, they will obtain a mark-up over and above their outside option which is the income they get while unemployed. But this prevents the provision of full insurance which is a characteristic of a first-best allocation. ${ }^{17}$ Clearly, with a binding resource constraint (6c) and perfect insurance, the optimal values of $w$ and $b$ are still given by (8) and (9), respectively.

The requirement that workers have no bargaining power could be seen as an important benchmark. ${ }^{18}$ In the context of this paper, it could also be seen as part of the optimal policy to be implemented. For example, the labor market could be organized in such a way that firms and workers first meet without exchanging any information on the wage rate. Then, firms make a take-it-or-leave-it offer to workers. ${ }^{19}$

Finally, the following corollary is an immediate consequence of the above lemma:

Corollary 1 The first-best allocation cannot be implemented when the Hosios condition holds, i.e. when the bargaining power of workers is equal the elasticity of the matching function $\eta(\theta)$.

The Hosios condition balances search externalities on both sides of the labor market such that, without government intervention, output is maximized. It is, however, inconsistent with the provision of perfect insurance. Since, in the first-best allocation, output is maximized and workers must have zero bargaining power, the optimal policy will need to

\footnotetext{
${ }^{17}$ In their benchmark case, Blanchard and Tirole (2008) also assume that the bargaining power of workers is nil. Thus, the first-best benchmark derived in this section is a dynamic counterpart to theirs.

${ }^{18}$ Hagerdorn and Manovskii (2008) argue that workers have a bargaining power close to 0.05, which suggests that this benchmark is not necessarily implausible.

${ }^{19}$ In an environment with Nash bargaining, an alternative solution, proposed by Lehmann and van der Linden (2007), consists in setting a marginal rate of income taxation equal to $100 \%$.
} 
correct the rates of job creation and job destruction for the failure of the Hosios condition to hold.

Stage 2 is solved by assuming free entry. Vacancies keep being created by entrepreneurs until the returns from doing so reduce to zero. More formally, the value $V$ of a vacant position solves:

$$
r V=-c+q(\theta)[J(1)+H-V] .
$$

This states that the return from a vacancy consists of the flow cost $c$ of recruitment and of the possibility of filling the position at rate $q(\theta)$ which yields the value of an active firm with productivity 1 . The employer also qualifies for a hiring subsidy $H$ when he hires a worker. Free entry implies:

$$
V=0
$$

The amount of job creation can then be determined by plugging (18) into (17) and by using the value of $J(1)$ deduced from (13) and (14). This gives:

$$
\frac{1-R}{r+\lambda}-F=\frac{c}{q(\theta)}-H
$$

The left hand side is the value of a new match to a firm, $J(1)$; while the right hand side corresponds to the expected cost of recruiting a worker. Equation (19) is our second implementability condition: the decentralized job creation condition.

At Stage 1, the government needs to choose the optimal policy. The corresponding implementability condition is the usual government budget constraint:

$$
(1-u) \tau+(1-u) \lambda G(R) F=u b+u \theta q(\theta) H .
$$

Revenues consist of payroll taxes paid by employed workers and of layoff taxes applied to the job destruction flow; while the expenses are the payment of benefits to the unemployed and of hiring subsidies to the flow of newly created jobs.

It is now straightforward to solve for the optimal policy by matching the implementability conditions of the decentralized economy to the equations that characterize the first-best allocation of resources. More specifically, $H$ and $F$ must be chosen such that (19) reduces to (10) and (15) to (11). This gives:

$$
\begin{gathered}
F-H=\eta(\theta) \frac{1-R}{r+\lambda}, \\
r F=b+\tau-\frac{\eta(\theta)}{1-\eta(\theta)} c \theta,
\end{gathered}
$$

where $\theta$ and $R$ are jointly determined by (10) and (11). These are key equations characterizing the optimal policy in the benchmark model. They ensure that the rate of job 
creation and job destruction prevailing in the decentralized economy coincide with the planner's optimum.

These conditions have a potentially insightful interpretation. Let us start with the implementation of the optimal level of job creation, (21). Equation (10) implies that, under free entry, firms should only capture a fraction $1-\eta(\theta)$ of the match surplus; otherwise, entry is too high and too many resources are allocated to recruitment. However, employers have all the bargaining power and this must be offset by setting a firing tax that exceeds the hiring subsidy such as to absorb a fraction $\eta(\theta)$ of the match surplus which reduces job creation to an efficient level.

Let us now turn to the interpretation of the equation implementing the optimal level of job destruction, (22). As can be seen from (15), a layoff tax only affects the threshold $R$ if firms discount the future, i.e. if $r>0$. Indeed, any match will eventually be destroyed and, hence, by not laying off its worker now, the firm is only postponing the payment of the tax. Thus the relevant cost imposed by the layoff tax is $r F$, rather than just $F$.

A firm that dismisses its worker imposes a double externality on the financing of unemployment insurance. First, the worker will qualify for benefits and, second, he will no longer contribute to its funding by paying payroll taxes. The layoff tax should therefore be sufficiently high to ensure that employers internalize these effects. This is the main message of Blanchard Tirole (2008). ${ }^{20}$ The additional insight that is obtained by extending the analysis to a dynamic context is that there is also a social benefit from laying off a worker: it allows a desirable reallocation of this worker from a low to a high productivity job. This is captured by the third term of equation (22) which was given an intuitive interpretation when the optimal allocation was derived, cf. equation (12). This effect reduces the net social cost of dismissal and, hence, the level of the optimal layoff tax. Interestingly, the option value of keeping the match alive is properly taken into account by firms and therefore does not affect the size of the optimal layoff tax.

The level of payroll taxes is simply pinned down by the remaining implementability constraint, i.e. by the government budget constraint, (20). Using the fact that, in steady state, the job destruction flow is equal to the job creation flow, $(1-u) \lambda G(R)=u \theta q(\theta)$, we obtain:

$$
\tau=\frac{u}{1-u}[b-\theta q(\theta)(F-H)] .
$$

An important insight from this analysis is that the job destruction side of the economy determines the level of layoff taxes, $F$; while the job creation side determines the difference between layoff taxes and hiring subsidies, $F-H$. Note that this result is fundamentally

\footnotetext{
${ }^{20}$ In fact, in Blanchard Tirole (2008) payroll taxes do not appear as they should optimally be set equal to zero. However, Cahuc and Zylberberg (2008), who propose a generalization to the case where the government needs to raise taxes on income in order to redistribute wealth across heterogeneous individuals, did explicitly have them affecting the level of layoff taxes.
} 
due to the implementability conditions, (15) and (19), and will therefore remain true in all extensions of the benchmark model. An important implication, which follows from (23), is that the share of unemployment benefits financed from payroll taxes is essentially determined from the job creation side of the economy, a margin that is absent from Blanchard Tirole (2008).

Further insights on the optimal level of payroll taxes can be gained by replacing $F-H$ in (23) by its value from (21), which, after some straightforward rearrangement using (10), yields:

$$
\tau=\frac{u}{1-u}\left[b-\theta q(\theta)\left[\frac{1-R}{r+\lambda}-\frac{c}{q(\theta)}\right]\right] .
$$

The flow $b$ of unemployment benefits constitutes the social cost of having an unemployed worker. The second term represents the corresponding social benefit. Indeed, at rate $\theta q(\theta)$, an unemployed finds a job which generates a social value equal to the expected profits from production net of the recruitment costs.

Since the optimal rate of unemployment should ensure that the social benefit from joblessness is not too distant from its social cost, we expect the two terms of the main bracket of (24) to be close to each other. In fact, with time discounting, we expect the first term to be slightly larger than the second one since the benefit will only be realized in the future. This intuition is formally confirmed by rewriting the expression for the payroll tax, (24), as:

$$
\tau=\frac{r}{r+\lambda} u\left[\frac{y}{1-u}-R\right] .
$$

This expression is derived in Appendix A. Hence, without time discounting, i.e. $r=0$, payroll taxes are not part of the first-best policy. In this case, both unemployment insurance and hiring subsidies should be financed, exclusively, from layoff taxes.

The intuition is that the optimal rate of unemployment is such that the social cost is equal to the social benefit of having an unemployed worker. The key element is that, with free entry and zero bargaining power to workers, the social benefit is entirely captured by the government as fiscal revenue. Similarly, the social cost, i.e. the unemployment benefits, is a government expense. Hence, the two cancel out of the budget constraint and payroll taxes can be set equal to zero.

The optimal policy can now be fully characterized.

Proposition 1 When workers are wage takers, the first-best allocation can be implemented in a decentralized economy by choosing the values of the policy instruments $b, H$, $F$ and $\tau$ that jointly satisfy equations (9), (21), (22) and (25).

Knowing that the first-best allocation is implementable, we can derive the equilibrium rate of unemployment by setting $\dot{u}=0$ in equation (6a) determining the dynamics of 
unemployment. This yields the well known expression:

$$
u=\frac{\lambda G(R)}{\lambda G(R)+\theta q(\theta)}
$$

where $\theta$ and $R$ are jointly determined by (10) and (11). This equation nevertheless has an interesting new interpretation in this framework. Whereas, with risk-neutral workers, this is the output maximizing rate of unemployment ${ }^{21}$; here, given the microfoundations laid in terms of risk-averse workers, this is the optimal rate of unemployment. Not only could unemployment be too low from an output maximization perspective, it could also be too low from a welfare point of view, which is conceptually very different.

Here, the output maximizing and optimal rates of unemployment coincide. However, this only occurs because full insurance is provided at the optimum. For instance, assume that there is a fixed non-insurable utility cost $B>0$ of being unemployed. Thus, in the planner's problem (5), social welfare at each instant is given by $(1-u) v(w)+$ $u[v(x+b)-B]$ (rather than $(1-u) v(w)+u v(x+b))$. This specification is consistent with the happiness literature which has provided extensive evidence that unemployment has a long-lasting negative effect on life satisfaction. ${ }^{22}$

As the unemployed's marginal utility of consumption is not affected by $B$, it remains optimal to set $w=z+b$. The welfare loss from unemployment is therefore not insurable. It can be shown that the planner nevertheless finds it optimal to mitigate the problem by reducing the rate of job destruction below its output maximizing level such as to reduce the rate of unemployment. Thus, in that case, the optimal rate of unemployment is below the output maximizing rate of unemployment.

\section{Workers with Bargaining Power}

Under risk aversion, it is desirable to suppress any fluctuations in income between employment and unemployment spells. Hence, the implementation of a first-best allocation requires workers to have zero bargaining power, as stated in Lemma 1. However, it could be objected that workers fundamentally do have some bargaining power and that this cannot be influenced by the planner. Thus, when solving for the optimal policy, the expression for the wage rate resulting from the bargaining process should be added as an extra constraint to the planner's problem.

An obvious limitation of the analysis of this section is that it does not allow for private savings. ${ }^{23}$ When workers have some bargaining power, their income fluctuates over time

\footnotetext{
${ }^{21}$ This is often referred to as the "efficient rate of unemployment" in the search and matching literature with risk-neutral workers.

${ }^{22}$ See, for example, Clark Diener Georgellis Lucas (2008).

${ }^{23}$ Unfortunately, this limitation is not uncommon. Indeed, most of the papers mentioned in the
} 
which should induce them to accumulate some precautionary savings in order to avoid sharp drops in consumption when unemployed. It should nevertheless be acknowledged that, in practice, many employees hardly accumulate any savings. Wolff (1998) reports that, in 1995, the mean net worth of the lowest two quintiles of the wealth distribution in the U.S. amounted to only $\$ 900$. If we exclude home equity, which is not sufficiently liquid to provide adequate insurance against unemployment, the mean net worth of the bottom $40 \%$ of the population was minus $\$ 10600$. These workers with negative financial wealth are very likely to be borrowing constrained while unemployed, i.e. they cannot increase their borrowings such as to consume more than their current income. This evidence suggests that the no-savings benchmark is empirically relevant for a significant fraction of workers, especially at the lower end of the skill distribution. Hence, assuming that workers can easily accumulate some precautionary savings is not necessarily more realistic than assuming that workers have to consume their cash-on-hand at each instant. Moreover, allowing for private savings would reduce the demand for insurance but would presumably not fundamentally change the qualitative insights which I emphasize in this section.

\subsection{The Planner's Problem}

Before setting up the planner's problem, it is necessary to solve the bargaining problem between the worker and the firm.

When a match is formed, the firm and the worker bargain over an entire wage schedule, as a function of productivity, $\{w(x)\}_{x \in[R, 1]}$, and on a job destruction threshold $R$. Indeed, as the firm is risk-neutral and the worker risk-averse, it is quite natural that they initially bargain on a state-contingent contract which allows the risk-neutral firm to commit to absorb some of the future productivity risk facing the match. This employment contract is determined by Nash bargaining. If an agreement is not reached, the employer does not receive the hiring subsidy but does not have to pay the layoff tax. Thus, the employment contract is determined by:

$$
\left\{\{w(x)\}_{x \in[R, 1]}, R\right\}=\arg \max _{\left\{\left\{w_{i}(x)\right\}_{x \in\left[R_{i}, 1\right]}, R_{i}\right\}}\left[W_{i}(1)-U\right]^{\beta}\left[J_{i}(1)+H-V\right]^{1-\beta},
$$

where the expected utility of an unemployed, $U$, and of an employed worker in match $i$

introduction on the optimal provision of unemployment insurance within matching models of the labor market also abstract from private savings. 
with productivity $x, W_{i}(x)$, are implicitly given by:

$$
\begin{gathered}
r U=v(z+b)+\theta q(\theta)[W(1)-U], \\
r W_{i}(x)=v\left(w_{i}(x)\right)+\lambda \int_{R_{i}}^{1} W_{i}(s) d G(s)+\lambda G\left(R_{i}\right) U-\lambda W_{i}(x),
\end{gathered}
$$

where, as before, $v($.$) stands for the instantaneous utility of consumption. { }^{24}$ The subscript $i$ in the bargaining problem (27) and in the value of employment to a worker (29) is used to stress that the wage rates and the threshold productivity bargained in match $i$ do not affect the values of the outside options, i.e. the values of $U$ or $V$.

The implicit contract literature suggests that risk-neutral firms might be willing to provide their risk-averse workers with insurance against unemployment. However, note that, in the absence of savings, a severance payment cannot be used as an insurance device. If, instead, firms are allowed to provide unemployment insurance to their former employees until they receive a job offer, then they will choose to provide perfect insurance. In that situation, as in the benchmark case of Section 3, the government can implement the first-best allocation of resources and the corresponding policy can easily be characterized analytically. However, this case is neither theoretically interesting nor empirically relevant. Hence (as mentioned in footnote 2), I rule out transfers from a firm to a worker after their work relationship has ended.

As shown in Appendix B, the wage schedule and the job destruction threshold that solve (27) are jointly determined by the following three equations. First, the wage rate is independent of productivity:

$$
w(x)=w \text { for all } x \in[R, 1]
$$

Thus, the risk-neutral firm absorbs all the productivity risk. The worker's net salary $w$ is determined by:

$$
\frac{v(w)-v(z+b)}{v^{\prime}(w)}=[r+\lambda G(R)+\theta q(\theta)] \frac{\beta}{1-\beta} \frac{c}{q(\theta)}
$$

and the job destruction threshold solves:

$$
R=w+\tau-r F-\frac{\lambda}{r+\lambda} \int_{R}^{1}(s-R) d G(s)-\frac{r+\lambda G(R)}{r+\lambda G(R)+\theta q(\theta)} \frac{v(w)-v(z+b)}{v^{\prime}(w)} .
$$

Note that the last term of this job destruction condition would not appear in the absence of commitment, cf. (15). This shows that firms use both margins to provide insurance

\footnotetext{
${ }^{24}$ The value of a producing firm with productivity $x, J(x)$, is given by (13) with the wage rate indexed to productivity $x$.
} 
to risk-averse workers: they pay a constant wage and they lower the job destruction threshold.

Relying on the free-entry condition, Appendix $\mathrm{C}$ shows that the decentralized job creation condition is:

$$
(1-\beta)\left[\frac{1-R}{r+\lambda}+H-F\right]=\frac{c}{q(\theta)} .
$$

The optimal policy can then be derived by adding the wage equation (31) as a constraint to the original problem. Thus, the planner should maximize (5) with respect to $\theta, R$, $b$ and $w$ subject to (6a), (6b), (6c) and (31). The three remaining implementability constraints, (32), (33) and (20), can be left out since they jointly determine $F, H$ and $\tau$ which do not appear elsewhere in the planner's problem.

It turns out that, unlike in the case without bargaining power, the first-order conditions to the planner's problem are cumbersome and hardly interpretable. Hence, I first perform a reasonable calibration of the model. I then rely on numerical simulations of the optimal policy for different values of the bargaining power of workers in order to provide a number of key qualitative insights.

\subsection{Calibration}

Empirical studies have provided some support for a constant elasticity of the matching rate with respect to the unemployment rate (Petrongolo Pissarides 2001). Let $\eta$ be this fixed elasticity. We must therefore have:

$$
q(\theta)=q_{0} \theta^{-\eta},
$$

where the two parameters, $q_{0}$ and $\eta$, need to be calibrated. Following Mortensen and Pissarides (2003), the distribution of idiosyncratic shocks is assumed to be uniform on $[\psi, 1]$; hence its c.d.f. is:

$$
G(x)=\frac{x-\psi}{1-\psi}
$$

Finally, I use a standard constant relative risk aversion (CRRA) instantaneous utility function with CRRA coefficient $\phi$ :

$$
v(x)=\frac{x^{1-\phi}-1}{1-\phi}
$$

I calibrate my model to the US economy assuming that, currently, the government only intervenes to provide unemployment benefits $b$ which are entirely financed by payroll taxes $\tau$. I perform a monthly calibration. I set $r=0.004$, which implies a yearly interest rate of $4.8 \%$. Workers are characterized by a coefficient $\phi$ of relative risk aversion equal to 3. I take the elasticity $\eta$ of the matching function to be equal to 0.5 , which is in 
the mid-range of the empirical estimates reported by Petrongolo and Pissarides (2001). The calibration is performed assuming that workers and firms have equal bargaining power, i.e. $\beta=0.5$. Hall and Milgrom (2008) argue that the income-equivalent of being unemployed is equal to $71 \%$ of the average match productivity, a third of which consists of unemployment benefits. I therefore impose $z+b=0.71 y /(1-u)$ together with $2 b=z$, where $y /(1-u)$ is the average match productivity. To balance the government budget constraint, the payroll taxes $\tau$ must be set equal to $b u /(1-u)$. The flow cost $c$ of posting a vacancy is calibrated such that the equilibrium market tightness $\theta$ is equal to 0.72 , consistently with the empirical evidence reported by Pissarides (2009). As in Mortensen and Pissarides (2003), I assume that the productivity of a new match can drop by up to $35 \%$ when it is hit by an idiosyncratic shock, i.e. $\psi=0.65$. Finally, the scale parameter $q_{0}$ of the matching function and the rate $\lambda$ of occurrence of idiosyncratic shocks are jointly calibrated such that the monthly job finding rate is 0.45 while the unemployment rate is $5.5 \%$, consistently with the empirical evidence provided by Shimer (2012). The parameter values implied by this calibration are all displayed in Table 1.

Table 1: Exogenous parameter values

\begin{tabular}{cccccccc}
\hline$r$ & $\phi$ & $\eta$ & $z$ & $c$ & $\lambda$ & $q_{0}$ & $\psi$ \\
\hline 0.004 & 3 & 0.5 & 0.471 & 0.519 & 0.032 & 0.530 & 0.65 \\
\hline
\end{tabular}

\subsection{Simulation}

The simulation results are reported in Table 2. As, in this section, I want to investigate the impact of the bargaining power $\beta$ of workers on the optimal policy, I report the solution to the planner's problem for four different values of $\beta$. The initial case, $\beta=0$, 
corresponds to the first-best benchmark of Section 3.

Table 2: Optimal policy under Nash bargaining

\begin{tabular}{|l|cccc|}
\hline$\beta$ & 0 & 0.25 & 0.5 & 0.75 \\
\hline \hline$\theta$ & 0.902 & 0.780 & 0.529 & 0.259 \\
$R$ & 0.934 & 0.932 & 0.925 & 0.904 \\
$u(\%)$ & 4.829 & 5.140 & 6.022 & 7.814 \\
$y$ & 0.946 & 0.942 & 0.932 & 0.910 \\
$w$ & 0.946 & 0.952 & 0.956 & 0.957 \\
$b$ & 0.475 & 0.363 & 0.281 & 0.218 \\
$\tau$ & 0.0003 & 0.0004 & 0.0008 & 0.0024 \\
$F$ & 1.685 & 1.441 & 1.181 & 0.833 \\
$H$ & 0.755 & 0.679 & 0.484 & 0.129 \\
$F-H$ & 0.930 & 0.762 & 0.697 & 0.704 \\
Welfare Loss $(\%)$ & 0 & 0.15 & 0.73 & 2.31 \\
Gross Job Flow & 0.0243 & 0.0241 & 0.0232 & 0.0211 \\
$(1-u) \tau / u b(\%)$ & 1.35 & 1.78 & 4.26 & 12.92 \\
\hline
\end{tabular}

The welfare loss is computed as the proportional decline in consumption in the first-best case necessary to reach the new level of welfare. For example, when $\beta=0.5$, welfare is equal to what it would be in the first-best allocation, $\beta=0$, with consumption decreased by $0.73 \%$. In steady state, the gross job flow is given by $u \theta q(\theta)$ or, equivalently, by $(1-u) \lambda G(R)$. Finally, the last row reports the share of unemployment insurance expenses financed by payroll taxes.

It can easily be checked that, when the Hosios condition holds, i.e. when $\beta=\eta=$ 0.5 , output maximization requires $F=H$, such as to leave the rate of job creation undistorted. ${ }^{25}$ This would characterize the welfare maximizing policy if workers were risk-neutral. However, as can be seen from Table 2, such is not the case with risk-averse workers. Thus, when workers have some bargaining power, there is a trade-off between output maximization and insurance provision. More precisely, the planner sets layoff taxes higher than hiring subsidies in order to reduce entry and, hence, market tightness. This decreases wages ${ }^{26}$, which by relaxing the resource constraint, allows an increase in the level of unemployment benefits.

In a nutshell, the worker's bargaining power introduces a discrepancy between the wage rate $w$ and the income equivalent $z+b$ of being unemployed, which is detrimental

\footnotetext{
${ }^{25}$ This can easily be seen by comparing the decentralized job creation condition (33) to the first-best job creation condition (10).

${ }^{26}$ This can be seen from expression (31) for the wage rate while recalling that $q(\theta)$ is a decreasing function of $\theta$.
} 
to the provision of insurance. The planner responds by reducing market tightness such as to reduce this discrepancy, which enhances the provision of insurance.

Thus, when $\beta$ is low, $F$ is higher than $H$ in order to compensate for the failure of the Hosios condition to hold (as discussed in Section 3). As $\beta$ increases, this becomes a smaller concern, but insufficient insurance becomes a bigger one. The planner then wants to decrease market tightness which becomes the main reason why $F$ exceeds $H$.

Note that $F$ is so much higher than $H$ that it generates sufficient surplus to finance almost entirely the unemployment benefits. This is true even though, for all values of $\beta$, the magnitude of $F$ only amounts to less than two months of wage payments. This is more than sufficient to pay for the unemployment benefits given that either $\beta$ is low and the expected length of unemployment is short or $\beta$ is high and the replacement ratio is low.

The reservation threshold $R$ declines slightly with bargaining power in order to compensate for the imperfect provision of insurance. Indeed, at the margin, a decrease in $R$ reduces the rate of unemployment and, by (31), also reduces the gap between $w$ and $z+b$. But, this fall in $R$ comes at the cost of a more sclerotic labor market characterized by a lower reallocation of workers from low to high productivity jobs, as shown by the lower gross job flow.

The reduction in the rate of job creation being larger than that of job destruction, unemployment increases with $\beta$. Output, which in steady state can be written as $y=(1-u)\left[G(R)+\int_{R}^{1} s d G(s)\right]$, declines because a smaller number of people work, i.e. unemployment is higher, and the average productivity of employed workers is also reduced due to a lower reservation threshold.

In other words, the downward adjustment in $\theta$ and $R$, which enhances the provision of insurance, hinders the reallocation of workers from low to high productivity jobs, which reduces aggregate output. This is the essence of the trade-off between insurance and production. Also, it should be emphasized that a moderate amount of private savings is likely to reduce, but certainly not to eliminate, the demand for insurance. Thus, a trade-off would remain, albeit of a smaller magnitude, and the key qualitative insights about the optimal policy would presumably remain unaltered.

The wages and the job destruction threshold could be determined by directed search, rather than by Nash bargaining. In such an environment, competitive market makers jointly choose the wage schedule, the threshold and the length of queues, equal to $1 / \theta q(\theta)$, such as to maximize the expected utility of an unemployed worker subject to a free entry condition for firms; or more formally:

$$
\max _{\left\{\{w(x)\}_{x \in[R, 1]}, R, \theta\right\}} r U \text { subject to } V=0 .
$$


This yields exactly the same equations as (30), (31) and (32) with $\beta$ replaced by $\eta$. Thus, in Table 5 , directed search corresponds to the case where $\beta=\eta=0.5$. As implied by Corollary 1, directed search and the associated Hosios condition fail to implement a firstbest allocation of resources in an economy with risk-averse workers as they fail to entail a sufficient provision of insurance.

\subsection{Robustness}

So far, I have assumed that the firm is able to commit to a fixed employment contract. As a robustness check, it would be interesting to relax the commitment assumption, which would imply that wage bargaining occurs whenever the match is hit by a productivity shock. However, in such circumstances, due to risk-aversion, the resulting bargaining problem is intractable. ${ }^{27}$ Thus, following Blanchard and Tirole (2003), I consider that the wage rate is determined by surplus splitting (which would be the outcome of Nash bargaining without commitment if workers were risk-neutral).

In Appendix D, I solve numerically for the policy that maximizes the welfare of riskaverse workers when the wage rate is determined by surplus splitting. I first focus on the standard case where wage bargaining occurs each time the match is hit by a productivity shock. Alternatively, in the absence of commitment, it could seem natural to assume that the wage rate is re-bargained at each instant. In this latter case, the layoff tax raises the wage rate of the worker as soon as he is recruited. In both cases, it turns out that the main findings from the above analysis remain robust to the relaxation of the commitment assumption (as can be seen from Table D2 and D3, respectively). In particular, the layoff tax remains above the hiring subsidy such as to depress the rate of job creation which improves the provision of insurance.

Finally, I investigate the optimal policy under a naive surplus splitting rule whereby the wage rate at each instant is constrained to be independent of market tightness. ${ }^{28}$ Interestingly, it turns out that, in that case, market tightness $\theta$ and the reservation threshold $R$ turn out to be almost independent of the bargaining power of workers (see Table D4). Moreover, when the Hosios condition holds, i.e. when $\beta=0.5$, the layoff taxes and hiring subsidies are almost equal to each other. This suggests that, without the general equilibrium effect of market tightness on wages, there is hardly any trade-off between output maximization and insurance provision.

\footnotetext{
${ }^{27}$ With risk-averse workers, the Nash bargaining problem yields a continuum of integral equations (one for each $x \in[R, 1)$ and two for $x=1$ ) which jointly determines the equilibrium wage rate as a function of productivity. These would then have to be added as constraints to the planner's problem.

${ }^{28}$ For a match of productivity $x$, the wage rate is assumed to be equal to $w(x)=\beta[x-\tau]+(1-\beta)[z+b]$.
} 


\section{Moral Hazard}

So far, we have seen that, when workers have some bargaining power, the planner is always seeking to improve the provision of insurance. However, reducing the level of insurance might be a virtue if it increases the search intensity of unemployed workers. Indeed, concerns about the moral hazard effects of unemployment insurance have been at the heart of the literature on the topic. Hence, this section characterizes the optimal policy when job search monitoring is not available and, hence, when the unemployed freely choose their search intensity.

\subsection{Determination of Search Intensity}

Let $s$ denote the average search intensity of the unemployed. Vacant jobs and unemployed workers now get matched at rate $^{29}$ :

$$
m=m(s u, v)
$$

where the matching function satisfies the same properties as before. Vacancies become filled at rate:

$$
\frac{m(s u, v)}{v}=m\left(\frac{s}{\theta}, 1\right)=q(\theta, s)
$$

where market tightness remains defined as the ratio of vacancies to unemployment, i.e. $\theta=v / u$.

Unemployed worker $i$ who searches with intensity $s_{i}$ finds a job at rate:

$$
\begin{aligned}
\tilde{q}\left(\theta, s, s_{i}\right) & =\frac{s_{i}}{s} \frac{m(s u, v)}{u} \\
& =\frac{s_{i}}{s} \theta q(\theta, s) .
\end{aligned}
$$

The expected utility $U_{i}$ of unemployed worker $i$ is implicitly determined by:

$$
r U_{i}=v(z+b)-\sigma\left(s_{i}\right)+\tilde{q}\left(\theta, s, s_{i}\right)\left[W(1)-U_{i}\right]
$$

where $\sigma($.$) denotes an increasing and convex cost of search, with \sigma(0)=\sigma^{\prime}(0)=0$, and $W(1)$ is the value of a new job to a worker. The first-order condition for search intensity is:

$$
-\sigma^{\prime}\left(s_{i}\right)+\frac{\partial \tilde{q}\left(\theta, s, s_{i}\right)}{\partial s_{i}}\left[W(1)-U_{i}\right]=0
$$

Hence, using the symmetry which prevails in equilibrium, i.e. $s_{i}=s$ and $U_{i}=U$, the

\footnotetext{
${ }^{29}$ The intensity of job advertising made by vacant firms is exogenously set to 1 as, even if endogenously determined, it would not be affected by any policy parameters; cf. Pissarides (2000, chapter 5.3).
} 
search intensity of unemployed workers is implicitly determined by:

$$
s \sigma^{\prime}(s)=\theta q(\theta, s)[W(1)-U] .
$$

\subsection{The Planner's Problem}

The employment contract $\left\{\{w(x)\}_{x \in[R, 1]}, R\right\}$ is still determined by Nash bargaining as specified in (27) with the value of unemployment now given by:

$$
r U=v(z+b)-\sigma(s)+\theta q(\theta, s)[W(1)-U]
$$

where $s$ is determined by (43). Proceeding as before (cf. Appendix B), it can easily be established that the wage rate is still independent of productivity, i.e. $w(x)=w$ for all $x \in[R, 1]$, that this wage rate is determined by:

$$
\frac{v(w)-v(z+b)+\sigma(s)}{v^{\prime}(w)}=[r+\lambda G(R)+\theta q(\theta, s)] \frac{\beta}{1-\beta} \frac{c}{q(\theta, s)},
$$

and that the job destruction threshold solves:

$R=w+\tau-r F-\frac{\lambda}{r+\lambda} \int_{R}^{1}(x-R) d G(x)-\frac{r+\lambda G(R)}{r+\lambda G(R)+\theta q(\theta, s)} \frac{v(w)-v(z+b)+\sigma(s)}{v^{\prime}(w)}$.

Substituting the value of employment to a worker (29) and the value of unemployment (44) into the first-order condition for search intensity (43) yields:

$$
s \sigma^{\prime}(s)=\theta q(\theta, s) \frac{v(w)-v(z+b)+\sigma(s)}{r+\lambda G(R)+\theta q(\theta, s)} .
$$

Using the wage equation (45), this expression can be simplified to:

$$
s \sigma^{\prime}(s)=\frac{\beta}{1-\beta} c \theta v^{\prime}(w) .
$$

The planner's problem is the same as in the previous section with $s$ as a new control variable and either (47) or (48) as an additional constraint. ${ }^{30}$

\footnotetext{
${ }^{30}$ The other changes are that search intensity should be included in the matching function, i.e. $q(\theta)$ should be replaced by $q(\theta, s)$, and the search $\operatorname{cost} \sigma(s)$ should be subtracted from the objective function for a mass $u$ of unemployed workers, i.e. the last term of the objective should be $u[v(z+b)-\sigma(s)]$ instead of $u v(z+b)$.
} 


\subsection{Calibration}

The convex search cost is assumed to be given by a power function:

$$
\sigma(s)=k \frac{s^{\gamma+1}}{\gamma+1}
$$

where $k$ and $\gamma$ are positive parameters. I follow the same procedure as in the previous section to calibrate the model. In addition, I choose $k$ such that $s$ is normalized to 1 and $\gamma$ such that the elasticity of the unemployment duration with respect to the benefit level is equal to 0.3 , consistently with the recent empirical evidence provided by Landais (2012). ${ }^{31}$ The parameter values resulting from this calibration are displayed in Table 3.

Table 3: Exogenous parameter values with moral hazard

\begin{tabular}{cccccccccc}
\hline$r$ & $\phi$ & $\eta$ & $z$ & $c$ & $\lambda$ & $q_{0}$ & $\psi$ & $k$ & $\gamma$ \\
\hline 0.004 & 3 & 0.5 & 0.467 & 0.761 & 0.036 & 0.530 & 0.65 & 0.666 & 1.564 \\
\hline
\end{tabular}

\footnotetext{
${ }^{31}$ In their literature survey, Krueger and Meyer (2002) argue that it is reasonable to assume an elasticity of 0.5 . However, this elasticity is usually estimated for workers who do qualify for unemployment benefits. Following Hall and Milgrom (2008), to calibrate the model, I have assumed a low value of $b$ in order to capture the fact that, in practice, many unemployed workers do not receive any unemployment benefits. If only two thirds of unemployed workers are eligible for benefits, then their benefit level is equal to $3 / 2 b$ (while the others get nothing). If a $1 \%$ increase in $3 / 2 b$ raises the average length of unemployment by $0.5 \%$, then a $1 \%$ increase in $b$ raises the average length of unemployment by $0.33 \%$. This can be seen as an alternative justification for targeting a fairly low elasticity, i.e. a 0.3 elasticity of $1 / \theta q(\theta, s)$ with respect to $b$.
} 


\subsection{Simulation}

The simulation results are reported in Table 4.

Table 4: Optimal policy under Nash bargaining with moral hazard

\begin{tabular}{|l|ccccc|}
\hline$\beta$ & 0.125 & 0.25 & 0.3623 & 0.5 & 0.75 \\
\hline \hline$\theta$ & 1.164 & 1.015 & 0.857 & 0.659 & 0.315 \\
$R$ & 0.873 & 0.883 & 0.885 & 0.882 & 0.858 \\
$y$ & 5.036 & 4.952 & 5.080 & 5.398 & 6.482 \\
$w$ & 0.928 & 0.932 & 0.931 & 0.927 & 0.908 \\
$b$ & 0.910 & 0.923 & 0.931 & 0.937 & 0.942 \\
$s$ & 0.369 & 0.321 & 0.285 & 0.247 & 0.190 \\
$\tau$ & 0.584 & 0.758 & 0.865 & 0.966 & 1.106 \\
$F$ & 0.0002 & 0.0001 & 0.0003 & 0.0009 & 0.0036 \\
$H$ & 2.286 & 1.859 & 1.569 & 1.241 & 0.497 \\
$F-H$ & 1.452 & 1.175 & 0.959 & 0.694 & 0.057 \\
Welfare Loss (\%) & 0.834 & 0.684 & 0.610 & 0.547 & 0.441 \\
Gross Job Flow & 0.0220 & 0.0230 & 0.0232 & 0.0229 & 0.0203 \\
$(1-u) \tau / u b(\%)$ & 1.16 & 0.86 & 2.08 & 6.28 & 27.32 \\
\hline
\end{tabular}

The welfare of workers is maximized for $\beta=0.3623$. To see why there is such a welfare maximizing value of $\beta \in(0,1)$, note that, when the bargaining power of workers is very low, the provision of insurance is too high which results in excessively small incentives to search while unemployed. Conversely, a high bargaining power of workers results in an excessively small provision of insurance. Thus, $\beta=0.3623$ optimally balances the tradeoff between the provision of insurance and the provision of incentives to search while unemployed. The corresponding allocation is the one that the planner would choose to implement if he could freely set the wage rate. ${ }^{32}$ It can therefore be seen as the optimal allocation under moral hazard. The (consumption equivalent) welfare loss that is reported in Table 4 is computed relative to that welfare maximizing benchmark.

When workers have a smaller bargaining power, $\beta<0.3623$, search intensity is excessively low which is partially offset by the planner choosing a higher market tightness than in the benchmark. Indeed, a higher market tightness reduces the provision of insurance $^{33}$, which boosts the returns to search. Conversely, when $\beta>0.3623$, search intensity

\footnotetext{
${ }^{32}$ Indeed, allowing $\beta$ to be a control variable of the planner is equivalent to not imposing the equation for the wage rate that results from Nash bargaining, (45), as a constraint to the planner's problem.

${ }^{33}$ This can be seen from expression (45) for the wage rate while recalling that $q(\theta, s)$ is a decreasing function of $\theta$.
} 
is higher than in the optimal allocation. The previous intuitions, without moral hazard, dominate again and the planner decreases market tightness in order to enhance the provision of insurance. Thus, for high values of $\beta$, the introduction of moral hazard does not modify the qualitative conclusions of the previous section about the key characteristics of an optimal policy.

When the Hosios condition holds, i.e. when $\beta=0.5$, output (net of search costs) is again maximized when $F=H$. The fact that, with risk aversion, the planner chooses to set layoff taxes higher than hiring subsidies confirms that he seeks to reduce market tightness below the output maximizing level in order to enhance the provision of insurance.

Interestingly, when $\beta=0.3623$, the gross job flow is closed to being maximized. Indeed, when $\beta>0.3623$, market tightness is decreased which reduces the job creation flow; when $\beta<0.3623$, the low search intensity of unemployed workers also depresses the job creation flow.

In sum, the simulation results have revealed that the force pushing for more insurance, i.e. risk aversion, is only dominated by the force pushing for less insurance, i.e. moral hazard, for $\beta<0.3623$. It follows that moral hazard, and the resulting over provision of insurance, is only a dominant concern for rather low values of $\beta$.

Appendix E shows that this conclusion is robust to the relaxation of the commitment assumption. Indeed, under surplus splitting, for each value of $\beta$, the optimal allocation is very similar to the one reported in Table 4 and the welfare of workers is maximized for $\beta=0.34$ (cf. Table E2 and E3).

\section{Conclusion}

In this paper, I have investigated optimal policies in a dynamic search model of the labor market with risk-averse workers. More precisely, I have focused on the joint derivation of the optimal level of unemployment benefits, layoff taxes, hiring subsidies and payroll taxes.

I began by abstracting from moral hazard in order to focus on the general equilibrium effects of the different policy instruments. I have shown that the first-best allocation of resources can be implemented in a decentralized economy when workers are wage takers. In this situation, full insurance is provided and output is maximized. Layoff taxes are higher than hiring subsidies in order to prevent an excessive entry of vacancies induced by the absence of bargaining power of workers. The gap between layoff taxes and hiring subsidies generates a budgetary surplus which is sufficiently large to finance nearly all the unemployment benefits; payroll taxes are therefore hardly needed.

The analysis being properly microfounded with risk-averse workers, it naturally defines 
an optimal rate of unemployment which only coincides with the output maximizing rate of unemployment when full insurance can be provided, i.e. when there is no trade-off between the provision of insurance and the maximization of production.

When workers have some bargaining power, the planner wants to reduce wages in order to relax the resource constraint and improve the level of unemployment benefits. In particular, this is achieved by reducing market tightness which lowers wages, as desired, but also hinders the reallocation of workers from low to high productivity jobs. Introducing moral hazard adds a counteracting force to the model. When workers have a very low bargaining power, it is typically desirable to increase market tightness and to boost wages in order to enhance the incentive to search while unemployed. However, when workers have more substantial bargaining power, under-provision of insurance, rather than moral hazard, remains the primary concern of the planner.

By emphasizing the liquidity effect of unemployment insurance, Chetty (2008) has already argued that the issue of moral hazard might have been over-emphasized in the literature. The present paper adds to this by showing that general equilibrium effects on job creation, job destruction and wages might be at least as important for the determination of the optimal labor market policy. ${ }^{34}$

There are essentially two reasons which could justify setting layoff taxes higher than hiring subsidies; in which case the difference between the two could cover at least some of the costs of providing unemployment benefits. First, to compensate for the failure of the Hosios condition to hold; or, in other words, to reduce entry in order to save on recruitment costs when the bargaining power of workers is lower than the elasticity of the matching function. Second, in order to reduce wages, by reducing market tightness, when the provision of insurance is insufficient. Importantly, as the bargaining power of workers increases, the first reason becomes less relevant while the second becomes more important. This is why layoff taxes exceed hiring subsidies in all realistic calibrations of the model and for any bargaining power of workers.

Some important issues are left for further research. First, an accurate empirical knowledge of the main determinants of wages, at the macroeconomic level, is key for the optimal design of labor market policies. ${ }^{35}$ Knowing, quantitatively, how wages are affected by market tightness or by the different policy instruments is obviously essential if the planner wants to increase the provision of insurance at the smallest cost in terms of output. The precise specification of wages also crucially affects the implementability constraints. For instance, if layoff taxes and hiring subsidies are passed on to workers

\footnotetext{
${ }^{34}$ Krusell Mukoyama Sahin (2010) reach a similar conclusion, even though they abstract from the possibility of using hiring subsidies and firing taxes to affect the rates of job creation and job destruction.

${ }^{35}$ Blanchflower and Oswald (1994) provide extensive evidence of the negative impact of unemployment on wages. However, their work does not control for the number of vacancies and, hence, cannot identify the impact of market tightness on wages.
} 
through adjustment in wages, then they have a much smaller effect on the job creation and job destruction decisions of firms.

Throughout this paper, I have only considered time invariant policy instruments. In fact, in a dynamic context, it would be interesting to allow the level of unemployment benefits to be affected by the length of unemployment and that of layoff taxes and hiring subsidies to depend on the age of the match, among other things. Also, in the proposed model, the length of unemployment does not directly matter, only its rate does. ${ }^{36}$ This could be relaxed by assuming that the level of human capital depreciates during an unemployment spell ${ }^{37}$ or, more simply, by assuming that workers have a preference for shorter spells even if this is associated with a higher probability of being unemployed. The length of unemployment being decreasing in market tightness, the resulting optimal policy would presumably advocate for a smaller reduction in the rate of job creation.

\section{References}

[1] Acemoglu, D. and Shimer, R. (1999), 'Efficient Unemployment Insurance', Journal of Political Economy, 107(5), 893-928.

[2] Acemoglu, D. and Shimer, R. (2000), 'Productivity Gains from Unemployment Insurance', European Economic Review, 44, 1195-1224.

[3] Alvarez, F. and Veracierto, M. (2000), 'Labor-Market Policies in an Equilibrium Search Model', in NBER Macroeconomics Annual 2000, edited by Ben S. Bernanke and Kenneth Rogoff, Cambridge, MA: MIT Press.

[4] Alvarez, F. and Veracierto, M. (2001), 'Severance Payments in an Economy with Frictions', Journal of Monetary Economics, 47, 477-498.

[5] Azariadis, C. (1975), 'Implicit Contracts and Underemployment Equilibria', Journal of Political Economy, 83(6), 1183-1202.

[6] Baily, M.N. (1974a), 'Wages and Unemployment under Uncertain Demand', Review of Economic Studies, 41(1), 37-50.

[7] Baily, M.N. (1974b), 'Some Aspects of Optimal Unemployment Insurance', Journal of Public Economics, 10, 379-402.

\footnotetext{
${ }^{36}$ The length of unemployment nevertheless has an impact on the speed of the reallocation of workers from low to high productivity jobs.

${ }^{37}$ See the related analyses of Pavoni (2008) and Shimer Werning (2006) who determine the optimal unemployment insurance policy with human capital depreciation.
} 
[8] Bentolila, S. and Bertola, G. (1990), 'Firing Costs and Labour Demand: How Bad is Eurosclerosis?', Review of Economic Studies, 57(3), 381-402.

[9] Blanchard, O.J. and Tirole, J. (2008), 'The Joint Design of Unemployment Insurance and Employment Protection: A First Pass', Journal of the European Economic Association, 6(1), 45-77.

[10] Blanchflower, D.G. and Oswald, A.J. (1994), The Wage Curve, Cambridge, MA: MIT Press.

[11] Cahuc, P. and Lehmann, E. (2000), 'Should Unemployment Benefits Decrease with the Unemployment Spell?', Journal of Public Economics, 77, 135-153.

[12] Cahuc, P. and Malherbet, F. (2004), 'Unemployment Compensation Finance and Labor Market Rigidity', Journal of Public Economics, 88, 481-501.

[13] Cahuc, P. and Zylberberg, A. (2008), 'Optimum Income Taxation and Layoff Taxes', Journal of Public Economics, 92, 2003-2019.

[14] Chetty, R. (2006), 'A General Formula for the Optimal Level of Social Insurance', Journal of Public Economics, 90, 1879-1901.

[15] Chetty, R. (2008), 'Moral Hazard versus Liquidity and Optimal Unemployment Insurance', Journal of Political Economy, 116(2), 173-234.

[16] Chetty, R. and Saez, E. (2010), 'Optimal Taxation and Social Insurance with Endogenous Private Insurance', American Economic Journal: Economic Policy, 2(2), 85-114.

[17] Clark, A.E., Diener, E., Georgellis, Y. and Lucas, R.E. (2008), 'Lags and Leads in Life Satisfaction: A Test of the Baseline Hypothesis', Economic Journal, 118, F222-F243.

[18] Coles, M. and Masters, M. (2006), 'Optimal Unemployment Insurance in a Matching Equilibrium', Journal of Labor Economics, 24(1), 109-138.

[19] Feldstein, M. (1976), 'Temporary Layoffs in the Theory of Unemployment', Journal of Political Economy, 84(5), 937-958.

[20] Fella, G. and Tyson, C.J. (2011), 'Optimal Severance Pay in a Matching Equilibrium', Working Paper, Queen Mary.

[21] Fredriksson, P. and Holmlund, B. (2001), 'Optimal Unemployment Insurance in Search Equilibrium', Journal of Labor Economics, 19(2), 370-399. 
[22] Hagedorn, M. and Manovskii, I. (2008), 'The Cyclical Behavior of Equilibrium Unemployment and Vacancies Revisited', American Economic Review, 98(4), 1692-1706.

[23] Hall, R.E. and Milgrom, P.R. (2008), 'The Limited Influence of Unemployment on the Wage Bargain', American Economic Review, 98(4), 1653-1674.

[24] Hopenhayn, H.A. and Nicolini, J.P. (1997), 'Optimal Unemployment Insurance', Journal of Political Economy, 105(2), 412-438.

[25] Hopenhayn, H. and Rogerson, R. (1993), 'Job Turnover and Policy Evaluation: A General Equilibrium Analysis', Journal of Political Economy, 101(5), 915-938.

[26] Hosios, A.J. (1990), 'On the Efficiency of Matching and Related Models of Search and Unemployment', Review of Economic Studies, 57(2), 279-298.

[27] Krueger, A.B. and Meyer, B.D. (2002), 'Labor Supply Effects of Social Insurance', in Handbook in Public Economics, Volume 4, edited by A.J. Auerbach and M. Feldstein, Amsterdam: North-Holland.

[28] Krusell, P., Mukoyama, T. and Sahin, A. (2010), 'Labour-Market Matching with Precautionary Savings and Aggregate Fluctuations', Review of Economic Studies, $77,1477-1507$.

[29] Landais, C. (2012), 'Assessing the Welfare Effects of Unemployment Benefits Using the Regression Kink Design', Working Paper, London School of Economics.

[30] Lehmann, E. and van der Linden, B. (2007), 'On the Optimality of Search Matching Equilibrium When Workers are Risk Averse', Journal of Public Economic Theory, $9(5), 867-884$.

[31] L'Haridon, O. and Malherbet, F. (2009), 'Employment Protection Reform in Search Economies', European Economic Review, 53, 255-273.

[32] Ljungqvist, L. (2002), 'How do Layoff Costs Affect Employment?', Economic Journal, 112, 829-853.

[33] Ljungqvist, L. and Sargent, T.J. (2008), 'Two Questions about European Unemployment', Econometrica, 76(1), 1-29.

[34] Mongrain, S. and Roberts, J. (2005), 'Unemployment Insurance and Experience Rating: Insurance Versus Efficiency', International Economic Review, 46(4), 13031319.

[35] Mortensen, D.T. and Pissarides, C.A. (1994), 'Job Creation and Job Destruction in the Theory of Unemployment', Review of Economic Studies, 61, 397-415. 
[36] Mortensen, D.T. and Pissarides, C.A. (1999), 'New Developments in Models of Search in the Labor Market', in Handbook in Labor Economics, Volume 3, Part 2, edited by O. Ashenfelter and D. Card, Amsterdam: North-Holland.

[37] Mortensen, D.T. and Pissarides, C.A. (2003), 'Taxes, Subsidies and Equilibrium Labor Market Outcomes', in Designing Inclusion: Tools to Raise Low-End Pay and Employment in Private Enterprise, edited by Edmund Phelps, Cambridge University Press.

[38] Pavoni, N. (2009), 'Optimal Unemployment Insurance, with Human Capital Depreciation, and Duration Dependence', International Economic Review, 50(2), 323-362.

[39] Petrongolo, B., and Pissarides, C.A. (2001), 'Looking into the Black Box: A Survey of the Matching Function', Journal of Economic Literature, 39, 390-431.

[40] Pissarides, C.A. (2000), Equilibrium Unemployment Theory, 2nd Edition, Cambridge, MA: MIT Press.

[41] Pissarides, C.A. (2009), 'The Unemployment Volatility Puzzle: Is Wage Stickiness the Answer?', Econometrica, 77(5), 1339-1369.

[42] Schuster, P. (2010), 'Labor Market Policy Instruments and the Role of Economic Turbulence', Working Paper, University of St. Gallen.

[43] Shavell, S. and Weiss, L. (1979), 'The Optimal Payment of Unemployment Insurance Benefits over Time', Journal of Political Economy, 87(6), 1347-1362.

[44] Shimer, R. (2012), 'Reassessing the Ins and Outs of Unemployment', Review of Economic Dynamics, 15(2), 127-148.

[45] Shimer, R. and Werning, I. (2006), 'On the Optimal Timing of Benefits with Heterogeneous Workers and Human Capital Depreciation', Working Paper, University of Chicago.

[46] Tirole, J. (2010), 'From Pigou to Extended Liability: On the Optimal Taxation of Externalities under Imperfect Financial Markets', Review of Economic Studies, $77(2), 697-729$.

[47] Topel, R.H. (1983), 'On Layoffs and Unemployment Insurance', American Economic Review, 73(4), 541-559.

[48] Topel, R. and Welch, F. (1980), 'Unemployment Insurance: Survey and Extensions', Economica, 47(187), 351-379. 
[49] Wang, C. and Williamson, S.D. (2002), 'Moral Hazard, Optimal Unemployment Insurance and Experience Rating', Journal of Monetary Economics, 49, 1337-1371.

[50] Wolff, E.N. (1998), 'Recent Trends in the Size Distribution of Household Wealth', Journal of Economic Perspectives, 12(3), 131-150.

\section{A Payroll Tax in First-Best Policy}

Before deriving (25), it is necessary to rewrite the expression for the optimal value of $b$ given by equation (9).

$$
\begin{aligned}
b & =y-c \theta u-z(1-u) \\
& =y-c \theta u-\left[R-\frac{\eta(\theta)}{1-\eta(\theta)} c \theta+\frac{\lambda}{r+\lambda} \int_{R}^{1}(s-R) d G(s)\right](1-u) \\
& =(1-u) \frac{r}{r+\lambda}\left[\frac{y}{1-u}-R\right]+\frac{\eta(\theta)}{1-\eta(\theta)} c \theta(1-u)+\lambda G(R)(1-u) \frac{1-R}{r+\lambda}-c \theta u \\
& =(1-u) \frac{r}{r+\lambda}\left[\frac{y}{1-u}-R\right]+\theta q(\theta)\left[\frac{1-R}{r+\lambda}-\frac{c}{q(\theta)}\right]
\end{aligned}
$$

The second line was derived by using the optimal job destruction condition (11) to get rid of $z$. Note that, combining (6a) and (6b) while imposing the steady state conditions $\dot{u}=0$ and $\dot{y}=0$, implies that the steady state level of output can be expressed as

$y=(1-u)\left[G(R)+\int_{R}^{1} s d G(s)\right]$. To obtain the third line, and to get rid of the integral, I have used that expression for the steady state level of output and then rearranged the terms. Finally, to get the last line, I have used equation (12) to rewrite the second term of the third line and used the fact that, in steady state, $\lambda G(R)(1-u)=\theta q(\theta) u$ to rewrite the third term of the third line.

Substituting this expression for $b$ in (24) yields equation (25).

\section{B Solving the Nash Bargaining Problem}

Before solving the bargaining problem, we need to find an expression for $W_{i}(1)$ and $J_{i}(1)$ as a function of the wage rates and of the job destruction threshold. Taking the difference between the expression for $W_{i}(x)$, as given by (29), evaluated at productivity $s$ and the same expression at productivity 1 yields:

$$
W_{i}(s)=\frac{v\left(w_{i}(s)\right)-v\left(w_{i}(1)\right)}{r+\lambda}+W_{i}(1)
$$


Substituting this expression into the value of employment for a newly recruited worker, given by (29) with $x=1$, gives:

$$
W_{i}(1)=\frac{1}{r+\lambda G\left(R_{i}\right)}\left[v\left(w_{i}(1)\right)-\frac{\lambda}{r+\lambda} \int_{R_{i}}^{1}\left[v\left(w_{i}(1)\right)-v\left(w_{i}(s)\right)\right] d G(s)+\lambda G\left(R_{i}\right) U\right] .
$$

Similarly, using (13) with the wage indexed to productivity, the value of a firm when the match is created is given by:

$$
\begin{aligned}
J_{i}(1)= & \frac{1}{r+\lambda G\left(R_{i}\right)} \\
& \times\left[1-\left(w_{i}(1)+\tau\right)-\frac{\lambda}{r+\lambda} \int_{R_{i}}^{1}\left[\left(1-w_{i}(1)\right)-\left(s-w_{i}(s)\right)\right] d G(s)-\lambda G\left(R_{i}\right) F\right] .
\end{aligned}
$$

These two expressions imply that:

$$
\frac{\partial W_{i}(1)}{\partial w_{i}(1)}=\frac{v^{\prime}\left(w_{i}(1)\right)}{r+\lambda} \text { and } \frac{\partial J_{i}(1)}{\partial w_{i}(1)}=-\frac{1}{r+\lambda}
$$

also, for all $x \in\left[R_{i}, 1\right)$, we have:

$$
\frac{\partial W_{i}(1)}{\partial w_{i}(x)}=\frac{v^{\prime}\left(w_{i}(x)\right) \lambda g(x) d x}{[r+\lambda]\left[r+\lambda G\left(R_{i}\right)\right]} \text { and } \frac{\partial J_{i}(1)}{\partial w_{i}(x)}=-\frac{\lambda g(x) d x}{[r+\lambda]\left[r+\lambda G\left(R_{i}\right)\right]},
$$

where $g(x) \equiv d G(x) / d x$; and finally:

$$
\begin{aligned}
\frac{\partial W_{i}(1)}{\partial R_{i}}=-\frac{\lambda g\left(R_{i}\right)}{\left[r+\lambda G\left(R_{i}\right)\right]^{2}} & (\mathrm{~B} 3) \\
\times & {\left[v\left(w_{i}\left(R_{i}\right)\right)-r U+\frac{\lambda}{r+\lambda} \int_{R_{i}}^{1}\left[v\left(w_{i}(s)\right)-v\left(w_{i}\left(R_{i}\right)\right)\right] d G(s)\right], }
\end{aligned}
$$

and:

$$
\begin{aligned}
\frac{\partial J_{i}(1)}{\partial R_{i}} & =-\frac{\lambda g\left(R_{i}\right)}{\left[r+\lambda G\left(R_{i}\right)\right]^{2}} \\
& \times\left[R_{i}-\left(w_{i}\left(R_{i}\right)+\tau\right)+r F+\frac{\lambda}{r+\lambda} \int_{R_{i}}^{1}\left[\left(s-w_{i}(s)\right)-\left(R_{i}-w_{i}\left(R_{i}\right)\right)\right] d G(s)\right] .
\end{aligned}
$$

The first-order conditions for the wage $w_{i}(x)$ and the threshold $R_{i}$ are obtained by differentiating the logarithm of the Nash product in (27). This yields:

$$
\frac{\beta}{W_{i}(1)-U} \frac{\partial W_{i}(1)}{\partial w_{i}(x)}=\frac{1-\beta}{J_{i}(1)+H-V}\left(-\frac{\partial J_{i}(1)}{\partial w_{i}(x)}\right) \text { for all } x \in\left[R_{i}, 1\right]
$$


and:

$$
\frac{\beta}{W_{i}(1)-U} \frac{\partial W_{i}(1)}{\partial R_{i}}=\frac{1-\beta}{J_{i}(1)+H-V}\left(-\frac{\partial J_{i}(1)}{\partial R_{i}}\right) .
$$

Now that the first-order conditions and the corresponding derivatives have been derived, we can drop the subscript $i$ and use the fact that in equilibrium, from symmetry, $w_{i}(x)=$ $w(x)$ and $R_{i}=R$.

Substituting the derivatives (B1) or (B2) into the first-order condition for the wage rate (B5) immediately reveals that the wage rate is independent of productivity, as stated by equation (30). Note that, with a fixed wage, the value functions for unemployment and employment, i.e. (28) and (29), jointly imply that:

$$
W-U=\frac{v(w)-v(z+b)}{r+\lambda G(R)+\theta q(\theta)}
$$

Substituting this expression together with $V=0, J(1)+H=c / q(\theta)$ and the derivatives of (B1) into the first-order condition for the wage rate (B5) yields equation (31) which implicitly determines the wage rate.

Note that the derivative (B3) can be simplified by using the fact that, from (28) and (B7), we have:

$$
v(w)-r U=[r+\lambda G(R)] \frac{v(w)-v(z+b)}{r+\lambda G(R)+\theta q(\theta)} .
$$

Substituting $V=0, J(1)+H=c / q(\theta)$, (B7), the derivative of the worker's welfare (B3) simplified with (B8) and the derivative of the firm's expected profits (B4) into the firstorder condition for the threshold (B6) gives an expression for the equilibrium threshold which can be simplified using (31) to give (32).

\section{The Decentralized Job Creation Condition When Workers Have Some Bargaining Power}

Taking the difference between the value of employment to a firm of productivity $x,(13)$, and that of a firm with productivity $R$ yields:

$$
J(x)=\frac{x-R}{r+\lambda}+J(R) .
$$

Substituting this expression into the value of employment to a firm, (13), with productivity $R$ gives:

$$
(r+\lambda) J(R)=R-(w+\tau)+\frac{\lambda}{r+\lambda} \int_{R}^{1}(s-R) d G(s)+\lambda[1-G(R)] J(R)-\lambda G(R) F
$$


or equivalently:

$$
[r+\lambda G(R)] J(R)=R-(w+\tau)+\frac{\lambda}{r+\lambda} \int_{R}^{1}(s-R) d G(s)-\lambda G(R) F .
$$

Substituting (31) into (32), the job destruction condition can be written as:

$$
R=w+\tau-r F-\frac{\lambda}{r+\lambda} \int_{R}^{1}(s-R) d G(s)-[r+\lambda G(R)] \frac{\beta}{1-\beta} \frac{c}{q(\theta)} .
$$

Substituting this expression into (C2) yields:

$$
J(R)=-F-\frac{\beta}{1-\beta} \frac{c}{q(\theta)} .
$$

Combining this expression with (C1) implies:

$$
J(1)=\frac{1-R}{r+\lambda}-F-\frac{\beta}{1-\beta} \frac{c}{q(\theta)}
$$

By the free-entry condition, $V=0$, and the value of a vacancy, (17), the job creation condition is:

$$
J(1)+H=\frac{c}{q(\theta)}
$$

Finally, combining (C3) and (C4) yields the decentralized job creation condition (33).

\section{Optimal Policy under Surplus Splitting}

Surplus splitting is the outcome of Nash bargaining without commitment when workers are risk neutral. Let $\tilde{U}$ denote the net present value of expected income of an unemployed worker, i.e. the value of unemployment to a risk-neutral worker. Similarly, the initial value of a match to a firm and to a (risk-neutral) worker are denoted by $J_{0}(1)$ and $\tilde{W}_{0}(1)$, respectively. The corresponding subsequent values, after an idiosyncratic shock has set the productivity of the match to $x$, are $J(x)$ and $\tilde{W}(x)$.

Wage bargaining occurs when the worker is recruited and each time the match is hit by a productivity shock. The initial wage, $w_{0}(1)$, is determined by the following surplus splitting rule:

$$
(1-\beta)\left[\tilde{W}_{0}(1)-\tilde{U}\right]=\beta\left[J_{0}(1)+H-V\right],
$$

which captures the fact that, in case no agreement is reached, the firm does not receive the hiring subsidy but does not have to pay the firing tax. Proceeding as in Mortensen 
Pissarides (2003) or Pissarides (2000, chapter 9), it can easily be established that ${ }^{38}$ :

$$
w_{0}(1)=\beta[1+c \theta-\tau-\lambda F+(r+\lambda) H]+(1-\beta)[z+b] .
$$

Once the match has been hit by an idiosyncratic shock, the surplus splitting rule for a match with productivity $x$ becomes:

$$
(1-\beta)[\tilde{W}(x)-\tilde{U}]=\beta[J(x)+H-V],
$$

which captures the fact that, in case the match dissolves, the firm has to pay the layoff tax. This yields:

$$
w(x)=\beta[x+c \theta-\tau+r F]+(1-\beta)[z+b] .
$$

It can easily be shown that, under surplus splitting, the job destruction conditions, determined by $J(R)=-F$, becomes:

$$
R=z+b+\tau+\frac{\beta}{1-\beta} c \theta-r F-\frac{\lambda}{r+\lambda} \int_{R}^{1}(s-R) d G(s),
$$

while the job creation condition, determined by the free-entry condition $V=0$, is:

$$
(1-\beta)\left[\frac{1-R}{r+\lambda}+H-F\right]=\frac{c}{q(\theta)}
$$

To determine the optimal policy, the implementability conditions, i.e. (D5), (D6) and (20), must be added as constraints to the planner's problem. Let $n$ denote the number of matches which have not been hit by an idiosyncratic shock yet and with prevailing wage $w_{0}(1)$. The optimal policy under surplus splitting is therefore the solution to:

$$
\max _{\{\theta, R, b, \tau, F, H\}} \int_{0}^{\infty} e^{-\rho t}\left[n v\left(w_{0}(1)\right)+(1-u-n) \int_{R}^{1} \frac{v(w(x))}{1-G(R)} d G(x)+u v(z+b)\right] d t
$$

\footnotetext{
${ }^{38}$ The layoff tax enters the expression for the initial wage rate as it affects the firm's expected profits from a newly created match.
} 


$$
\begin{array}{ll}
\text { subject to } \quad & \dot{u}=\lambda G(R)(1-u)-\theta q(\theta) u \\
& \dot{n}=\theta q(\theta) u-\lambda n \\
& \dot{y}=\theta q(\theta) u+\lambda(1-u) \int_{R}^{1} s d G(s)-\lambda y \\
& n w_{0}(1)+(1-u-n) \int_{R}^{1} \frac{w(x)}{1-G(R)} d G(x)+u b=y-c \theta u \\
& R=z+b+\tau+\frac{\beta}{1-\beta} c \theta-r F-\frac{\lambda}{r+\lambda} \int_{R}^{1}(s-R) d G(s) \\
& (1-\beta)\left[\frac{1-R}{r+\lambda}+H-F\right]=\frac{c}{q(\theta)} \\
& (1-u) \tau+(1-u) \lambda G(R) F=u b+u \theta q(\theta) H
\end{array}
$$

where the expressions for the wage rate, (D2) and (D4), should be substituted into the objective (D7) and into the resource constraint (D8d). The second constraint (D8b), which did not previously appear, keeps track of the dynamics of $n$.

Before performing a simulation of the optimal policy, the model needs to be calibrated. Following the same procedure as in Section 4.2 yields the parameters of Table D1.

Table D1: Exogenous parameter values under surplus splitting

\begin{tabular}{cccccccc}
\hline$r$ & $\phi$ & $\eta$ & $z$ & $c$ & $\lambda$ & $q_{0}$ & $\psi$ \\
\hline 0.004 & 3 & 0.5 & 0.472 & 0.338 & 0.029 & 0.530 & 0.65 \\
\hline
\end{tabular}

The simulation results are reported in Table D2 for four different value of $\beta$ (where, again, 
$\beta=0$ corresponds to the first-best benchmark).

Table D2: Optimal policy under surplus splitting

\begin{tabular}{|l|cccc|}
\hline$\beta$ & 0 & 0.25 & 0.5 & 0.75 \\
\hline \hline$\theta$ & 1.421 & 1.110 & 0.557 & 0.207 \\
$R$ & 0.950 & 0.947 & 0.938 & 0.915 \\
$n(\%)$ & 3.800 & 4.251 & 5.726 & 8.407 \\
$y$ & 0.823 & 0.814 & 0.777 & 0.694 \\
Average Wage & 0.959 & 0.954 & 0.938 & 0.907 \\
$b$ & 0.958 & 0.963 & 0.965 & 0.960 \\
$\tau$ & 0.486 & 0.360 & 0.291 & 0.255 \\
$F$ & 0.0002 & -0.0011 & -0.0041 & -0.0074 \\
$H$ & 1.410 & 1.244 & 1.220 & 1.353 \\
$F-H$ & 0.650 & 0.556 & 0.314 & -0.040 \\
Welfare Loss $(\%)$ & 0 & 0.17 & 0.93 & 2.81 \\
Gross Job Flow & 0.0240 & 0.0237 & 0.0227 & 0.0203 \\
$(1-u) \tau / u b(\%)$ & 1.12 & -6.84 & -23.00 & -31.53 \\
\hline
\end{tabular}

These results are largely consistent with the one that were obtained under commitment (cf. Table 2 of Section 4).

A second possibility is that the wage rate is re-bargained at each instant. This implies that newly employed workers are being paid $w(1)$ as given by (D4) instead of $w_{0}(1)$ given by (D2). The only implementability condition that is modified is the job creation condition which becomes:

$$
(1-\beta) \frac{1-R}{r+\lambda}+H-F=\frac{c}{q(\theta)}
$$

Thus, the planner's problem is as above, (D7), with $w_{0}(1)$ replaced by $w(1)$ and (D8f) 
replaced by (D9). The simulation results are reported in Table D3.

Table D3: Optimal policy under surplus splitting with immediate wage renegotiation

\begin{tabular}{|l|cccc|}
\hline$\beta$ & 0 & 0.25 & 0.5 & 0.75 \\
\hline \hline$\theta$ & 1.421 & 1.109 & 0.555 & 0.206 \\
$R$ & 0.950 & 0.949 & 0.948 & 0.942 \\
$u(\%)$ & 3.800 & 4.279 & 5.915 & 9.168 \\
$n$ & 0.823 & 0.819 & 0.801 & 0.757 \\
$y$ & 0.959 & 0.954 & 0.937 & 0.904 \\
Average Wage & 0.958 & 0.964 & 0.966 & 0.963 \\
$b$ & 0.486 & 0.355 & 0.284 & 0.245 \\
$\tau$ & 0.0002 & 0.0041 & 0.0102 & 0.0210 \\
$F$ & 1.410 & 1.060 & 0.726 & 0.404 \\
$H$ & 0.650 & 0.589 & 0.416 & 0.253 \\
$F-H$ & 0.760 & 0.471 & 0.309 & 0.151 \\
Welfare Loss $(\%)$ & 0 & 0.18 & 0.98 & 2.98 \\
Gross Job Flow & 0.0240 & 0.0239 & 0.0234 & 0.0221 \\
$(1-u) \tau / u b(\%)$ & 1.12 & 25.93 & 56.99 & 85.13 \\
\hline
\end{tabular}

The allocation of resources is almost identical to that of the previous case. The main difference lies in the level of the policy instruments $F, H$ and $\tau$. In particular, the difference between layoff taxes and hiring subsidies is smaller than before. This is primarily due to the larger impact that this difference has on the rate of job creation (as can be seen by comparing the new job creation condition (D9) with the previous one (D6)). Indeed, with immediate wage renegotiation, these policy instruments have a smaller effect on wages and, hence, a larger effect on firms. This explains why $F-H$ does not need to be as large as before to reduce $\theta$ to its desired level. Additionally, with immediate wage renegotiation, hiring subsidies cease to increase initial wages and layoff taxes cease to decrease them. Hence, when workers have strong bargaining power, it is no longer necessary to maintain high layoff taxes and low hiring subsidies to prevent these initial wages from being too high, which would be detrimental to insurance. Finally, $F-H$ being smaller than before, a significant share of unemployment benefits now need to be financed from payroll taxes.

Finally, I determine the optimal policy under a naive surplus splitting rule whereby the wage rate is constrained to be independent of market tightness. Thus, the wage rate for a match with productivity $x$ is given by:

$$
w(x)=\beta[x-\tau]+(1-\beta)[z+b] .
$$


Note that the wage rate is lower under naive surplus splitting (D10) than under continuous re-bargaining (D4) as market tightness and layoff taxes cease to have a positive impact. This generates a mechanical improvement in the provision of insurance.

The job creation condition remain given by (D9) while the job destruction condition becomes:

$$
R=z+b+\tau-\frac{r F}{1-\beta}-\frac{\lambda}{r+\lambda} \int_{R}^{1}(s-R) d G(s) .
$$

The simulation results are displayed in Table D4.

Table D4: Optimal policy under naive surplus splitting

\begin{tabular}{|l|cccc|}
\hline$\beta$ & 0 & 0.25 & 0.5 & 0.75 \\
\hline \hline$\theta$ & 1.421 & 1.422 & 1.423 & 1.424 \\
$R$ & 0.950 & 0.950 & 0.951 & 0.952 \\
$u(\%)$ & 3.800 & 3.804 & 3.813 & 3.828 \\
$n$ & 0.823 & 0.824 & 0.827 & 0.830 \\
$y$ & 0.959 & 0.959 & 0.959 & 0.959 \\
Average Wage & 0.958 & 0.959 & 0.959 & 0.959 \\
$b$ & 0.486 & 0.477 & 0.468 & 0.460 \\
$\tau$ & 0.0002 & 0.0095 & 0.0190 & 0.0284 \\
$F$ & 1.410 & 1.052 & 0.690 & 0.336 \\
$H$ & 0.650 & 0.679 & 0.708 & 0.736 \\
$F-H$ & 0.760 & 0.373 & -0.018 & -0.400 \\
Welfare Loss $(\%)$ & 0 & 0.001 & 0.004 & 0.010 \\
Gross Job Flow & 0.0240 & 0.0241 & 0.0241 & 0.0242 \\
$(1-u) \tau / u b(\%)$ & 1.12 & 50.52 & 102.44 & 155.06 \\
\hline
\end{tabular}

Market tightness $\theta$ and the productivity threshold $R$ are almost independent of the bargaining power of workers. Also, when the Hosios condition does hold, i.e. when $\beta=0.5$, layoff taxes and hiring subsidies are virtually equal to each other. ${ }^{39}$ These findings suggest that, without the general equilibrium effect of market tightness on wages, there is hardly any trade-off between output maximization and insurance provision.

\footnotetext{
${ }^{39}$ Indeed, when $\beta=\eta(\theta)$, the decentralized job creation condition (D9) is identical to the output maximizing job creation condition (10) provided that $F=H$. The slight discrepancy between $F$ and $H$ that remains when $\beta=\eta(\theta)$, and which results in payroll taxes covering $102.44 \%$ of the cost of providing unemployment insurance rather than $100 \%$, is due to the negative impact of payroll taxes on wages. Hence, the government tries to increase those taxes a little in order to decrease wages which, through a relaxation of the resource constraint, leads to an improvement in the level of unemployment benefits.
} 


\section{E Optimal Policy under Surplus Splitting and Moral Hazard}

Surplus splitting in the presence of moral hazard results in the following wage rates:

$$
\begin{aligned}
w_{0}(1) & =\beta[1+c \theta-\tau-\lambda F+(r+\lambda) H]+(1-\beta)[z+b-\sigma(s)], \\
w(x) & =\beta[x+c \theta-\tau+r F]+(1-\beta)[z+b-\sigma(s)],
\end{aligned}
$$

where the initial wage $w_{0}(1)$ applies until a shock occurs. The existence of the search cost $\sigma(s)$ lowers the value of unemployment, which is the outside option, and hence adversely affects wages.

Simple algebra reveals that search intensity is determined by the first order condition:

$$
s \sigma^{\prime}(s)=\theta q(\theta, s) \frac{E[v(w)]-v(z+b)+\sigma(s)}{r+\lambda G(R)+\theta q(\theta, s)},
$$

where:

$$
E[v(w)]=\left[1-\frac{\lambda}{r+\lambda}[1-G(R)]\right] v\left(w_{0}(1)\right)+\frac{\lambda}{r+\lambda} \int_{R}^{1} v(w(x)) d G(x) .
$$

The planner's problem is as in Appendix D, cf. (D7), with $s$ as a new control variable and (E3) as an additional constraint. ${ }^{40}$

Proceeding as in Section 5.2 to calibrate the model yields the parameter values of Table E1.

Table E1: Exogenous parameter values under surplus splitting with moral hazard

\begin{tabular}{cccccccccc}
\hline$r$ & $\phi$ & $\eta$ & $z$ & $c$ & $\lambda$ & $q_{0}$ & $\psi$ & $k$ & $\gamma$ \\
\hline 0.004 & 3 & 0.5 & 0.469 & 0.661 & 0.034 & 0.530 & 0.65 & 0.672 & 1.535 \\
\hline
\end{tabular}

\footnotetext{
${ }^{40}$ The other changes are that search intensity should be included in the matching function, i.e. $q(\theta)$ should be replaced by $q(\theta, s)$; the search $\operatorname{cost} \sigma(s)$ should be subtracted from the objective function for a mass $u$ of unemployed workers, i.e. the last term of the objective should be $u[v(z+b)-\sigma(s)]$ instead of $u v(z+b)$; finally, $z$ should be replaced by $z-\sigma(s)$ in the decentralized job destruction condition, (D8e).
} 
The simulation results are reported in Table E2.

Table E2: Optimal policy under surplus splitting with moral hazard

\begin{tabular}{|l|ccccc|}
\hline$\beta$ & 0.125 & 0.25 & 0.3384 & 0.5 & 0.75 \\
\hline \hline$\theta$ & 1.438 & 1.220 & 1.012 & 0.657 & 0.257 \\
$u(\%)$ & 0.887 & 0.897 & 0.898 & 0.893 & 0.864 \\
$n$ & 4.526 & 4.443 & 4.644 & 5.318 & 7.066 \\
$y$ & 0.646 & 0.674 & 0.676 & 0.658 & 0.570 \\
Average wage & 0.937 & 0.941 & 0.939 & 0.931 & 0.905 \\
$b$ & 0.919 & 0.932 & 0.939 & 0.945 & 0.945 \\
$s$ & 0.374 & 0.319 & 0.289 & 0.251 & 0.213 \\
$\tau$ & 0.581 & 0.774 & 0.860 & 0.958 & 1.039 \\
$F$ & 0.0006 & -0.0003 & -0.0013 & -0.0034 & -0.0065 \\
$H$ & 2.250 & 1.849 & 1.670 & 1.448 & 1.219 \\
$F-H$ & 1.507 & 1.217 & 1.031 & 0.705 & 0.131 \\
Welfare Loss $(\%)$ & 0.86 & 0.11 & 0 & 0.32 & 2.31 \\
Gross Job Flow & 0.0219 & 0.0229 & 0.0230 & 0.0224 & 0.0194 \\
$(1-u) \tau / u b(\%)$ & 3.60 & -2.23 & -9.45 & -24.26 & -40.04 \\
\hline
\end{tabular}

Under an optimal labor market policy, the welfare of workers is maximized when $\beta=$ 0.3384. The results of Table E2 are largely consistent with main conclusions drawn from Table 4 of Section 5.

When surplus splitting occurs at each instant, newly employed workers are paid $w(1)$ as specified by (E2) rather than $w_{0}(1)$ given by (E1). The planner's problem is obtained by adding the constraint for search intensity, given by (E3) with $w(1)$ replacing $w_{0}(1)$ in (E4), to the corresponding problem of Appendix D. ${ }^{41}$ The simulation results with surplus splitting at each instant are reported in Table E3.

\footnotetext{
${ }^{41}$ Appropriate adjustments for search intensity should be made as described in the previous footnote.
} 
Table E3: Optimal policy under surplus splitting with immediate renegotiation and moral hazard

\begin{tabular}{|l|ccccc|}
\hline$\beta$ & 0.125 & 0.25 & 0.3357 & 0.5 & 0.75 \\
\hline \hline$\theta$ & 1.399 & 1.202 & 1.009 & 0.657 & 0.259 \\
$R$ & 0.885 & 0.897 & 0.899 & 0.898 & 0.879 \\
$n(\%)$ & 4.562 & 4.471 & 4.672 & 5.406 & 7.419 \\
$y$ & 0.641 & 0.673 & 0.679 & 0.671 & 0.605 \\
Average wage & 0.936 & 0.941 & 0.939 & 0.932 & 0.906 \\
$b$ & 0.919 & 0.933 & 0.939 & 0.946 & 0.949 \\
$s$ & 0.374 & 0.319 & 0.289 & 0.249 & 0.208 \\
$\tau$ & 0.579 & 0.774 & 0.860 & 0.965 & 1.054 \\
$F$ & 0.0016 & 0.0032 & 0.0042 & 0.0068 & 0.0126 \\
$H$ & 2.214 & 1.741 & 1.507 & 1.143 & 0.660 \\
$F-H$ & 1.502 & 1.251 & 1.097 & 0.834 & 0.479 \\
Welfare Loss $(\%)$ & 0.84 & 0.11 & 0 & 0.33 & 2.40 \\
Gross Job Flow & 0.0218 & 0.0229 & 0.0231 & 0.0228 & 0.0206 \\
$(1-u) \tau / u b(\%)$ & 9.21 & 21.30 & 29.77 & 47.58 & 75.90 \\
\hline
\end{tabular}

Here, the welfare of workers is maximized for $\beta=0.3357$. For each value of $\beta$, the allocation is almost identical to the one obtained without immediate wage renegotiation. The optimal setting of the policy instruments is different, but these differences are similar to those obtained between the corresponding tables without moral hazard (cf. Table D2 and D3). 